\title{
HISTORICIDAD DEL RECONOCIMIENTO FEMENINO EN CONTRASTE CON LA PARTICIPACIÓN ESCOLAR: UNA MIRADA INTERCULTURAL, DEPARTAMENTO DEL ATLÁNTICO-CARIBE COLOMBIANO
}

1 Trabajadora Social. Doctora en Educación Intercultural. Docente-Investigadora. Grupo: Estudios del Caribe. Universidad Simón Bolívar, Barranquilla, Colombia. aaguilar2@unisimonbolivar.edu.co 


\section{RESUMEN}

El enfoque intercultural ha tenido importancia, no solo desde el concepto, sino desde las reivindicaciones socioculturales que han tenido los distintos conglomerados sociales que aunando fuerzas han logrado visibilizarse a nivel global. En el caso del lado femenino, marcan procesos válidos de incorporación de la mujer en los distintos planos públicos y privados. Es desde el entorno escolar, un lugar primario fundamental para que en la praxis de la participación, pueda ampliarse al ejercicio democrático como tal. En ese sentido, en el presente capítulo se presenta un contraste con el devenir histórico de la presencia femenina en la historicidad acumulada, desde sus reivindicaciones civiles, educativas, participativas; como a su vez acciones desde la política pública, organismos internacionales y académicos, que dan muestra de la importancia de los temas en inclusión del género femenino, que finalmente se cruzan con estudios realizados en las Instituciones Educativas en el departamento del Atlántico-Caribe colombiano en torno al liderazgo que desarrollan las líderes estudiantiles y las reivindicaciones que, como proceso, aportan los directivos y docentes, garantes de los derechos y los reconocimientos que se otorgan desde bases legales. Todo ello a través de una metodología cualitativa, mediante entrevistas a profundidad, grupos focales y observación documental, lo que permitió identificar interacciones cotidianas, que marcan importancia desde la igualdad y libertad, para que en el caso de las líderes estudiantiles, se apropien autónomamente de su desarrollo en la sociedad global, lejos de los parámetros que tradicionalmente han asignado a la mujer y a la representación femenina.

\section{RECONOCIMIENTOS FEMENINOS A PARTIR DE MOVI- MIENTOS SOCIALES DEL SIGLO XVIII}

El reconocimiento tardío, desde lo legal a la incorporación de la mujer, en temas tan fundamentales como la educación, la par- 
ticipación social, y consecuentemente, en ámbitos como la cultura, la ciencia, la filosofía, la salud sexual y reproductiva, como en otros temas se han propiciado favorablemente, por antecedentes contextuales, liderados por las propias mujeres en diferentes puntos del planeta, comenzando por los niveles más desarrollados, hasta ir logrando una incorporación gradual de las mujeres sin distingo de su color, adscripción de género, nivel social, etnia e ideología. En ese sentido, se describen en adelante, los logros desde la proclama de los derechos de la mujer y la ciudadana en 1791, en oposición a los derechos del ciudadano. De allí el origen de todo un despliegue por más de tres siglos, que tanto en el contexto internacional, latinoamericano y nacional, se detallan a continuación.

\section{Movilizaciones socioculturales de la mujer}

Con la celebración de acontecimientos que no tienen preexistencia antes del siglo XVIII, contextualmente hay cuatro acciones desde la política pública que han sido fundamentales para que muchas mujeres en el mundo puedan acceder a derechos plenos y al disfrute de mayor inclusión y participación sociocultural, en el mundo de la vida universal; todo, orientado por la movilidad social que historicamente ha tenido la mujer en la participación de revoluciones como la francesa y rusa, en la búsqueda de su emancipación. La primera, liderada por los movimientos sociales inicia desde finales del siglo XVIII y hasta el XXI. La segunda, se vincula con la comunidad internacional liderada por la ONU, inicia desde 1975 una serie de conferencias mundiales (México, 1975; Copenhague, 1980; Nairobi, 1985, y Beijing, 1995) para analizar la situación de la mujer, marcada por los inicios de estudios feministas, que permitían comprensiones de segundo orden. La tercera, es mediada por una práctica que cambió la vida reproductiva para las mujeres desde 1951, como 
fue la creación de la píldora anticonceptiva, lo cual definiría el control de la natalidad. Y la cuarta, en la que a partir de la última Conferencia Mundial de la Mujer en Beijing (1995), los gobiernos asistentes instan a la transversalización del género en la política pública.

Es así como la asimetría, integrada entre lo masculino/femenino, es un debate que se visibiliza a finales del siglo XVIII en la proclamación de los derechos del hombre y el ciudadano en 1789 y allí las mujeres que habían participado en la Revolución Francesa, entre ellas, Olympe de Gauges, quien contradictoriamente para la época manifiesta su interés de inclusión al género femenino cuando elabora y hace pública la declaración de los derechos de la mujer y de la ciudadana, en réplica a la declaración de los derechos del hombre y el ciudadano, por considerar que excluía a las mujeres. En ella reclamaba para la mujer los mismos derechos en cuanto a la igualdad, libertad y participación en espacios políticos, que no se reconocieran exclusivamente para el hombre. Señala además, que "la ignorancia, el olvido y el desprecio de los derechos de la mujer son las únicas causas de los males públicos y de la corrupción de los gobiernos (De Gauges, 1791, p.156) (La llustración no cumplió sus promesas en cuanto a la mujer se refiere, quedando lo femenino como aquel reducto que las luces no supieron o no quisieron iluminar; abandonando, por tanto, a la mitad de la especie en aquel ángulo sombrío de la pasión, la naturaleza o lo privado).

Este sería el inicio de las luchas reivindicativas que emprendiera el feminismo, en búsqueda de la igualdad inicialmente en Europa y Estados Unidos desde la inclusión en la educación (siglo XVIII) y luego como ciudadanas al obtener el derecho al sufragio (siglo XIX). Con estos logros, en la actualidad se busca 
una autonomía que permita un mejor sentido de autoasignación, que lejos de las heterodesignaciones como legado de la época patriarcal, facilite un posicionamiento favorable ubicándola más allá de la protesta en la propuesta.

Durante el último siglo, se destacan algunos momentos claves en la evolución histórica de los derechos de las mujeres en el ámbito multilateral, así como la adopción de instrumentos que establecen derechos para las mujeres en materia de nacionalidad, de protección en conflictos armados, frente a delitos como la trata y el tráfico de personas y de combate a la discriminación, entre otros; existiendo en este sentido según la ONU Mujeres (2012) una selección de 32 resoluciones, convenios y acuerdos mundiales en beneficio de los derechos de la mujer, a partir de la declaración de los derechos humanos que integran su protección (ver Tabla 2). Son el soporte de los avances en materia de legalidad de la mujer, para que en gran medida los países reconozcan los derechos de las mujeres y se mantenga la fuerza por la igualdad y equidad de género en todos los ámbitos, siendo necesarios el conocimiento de los derechos legales, de los compromisos asumidos por los gobiernos de manera voluntaria y de los mecanismos que permiten su cumplimiento.

A pesar de que el marco normativo para promover la igualdad de género se ha ido perfeccionando constantemente, sigue existiendo un evidente desfase entre los derechos garantizados "sobre el papel" y la situación real (OIT, 2004, p.5).

Es así como desde la fundación de la Organización de las Naciones Unidas (ONU) en 1945, los Estados reafirmaron la igualdad entre hombres y mujeres y se comprometieron a promover el respeto universal de los derechos humanos y de las libertades 
fundamentales de todos y todas sin hacer distinción por motivos de raza, sexo, idioma o religión, y a hacer efectivos tales derechos y libertades. Sería entonces a partir de 1948, cuando se promulga la Declaración Universal de los Derechos Humanos, considerando que los pueblos de las Naciones Unidas han reafirmado en la carta su fe en los derechos fundamentales del hombre, en la dignidad y el valor de la persona humana y en la igualdad, declarándose resueltos a promover el progreso social y a elevar el nivel de vida dentro de un concepto más amplio de la libertad (ONU, 2012).

De esa manera, los tres primeros decenios de su actividad, la ONU se centró en la promoción de los derechos políticos, como también, civiles de las mujeres y la recopilación de datos sobre la condición jurídica y social de las mujeres en todo el mundo. Sin embargo, con el tiempo se comprobó que el reconocimiento del derecho de las mujeres al voto o la promulgación de leyes no bastaban por sí mismos para garantizar el pleno disfrute de los derechos políticos de las mujeres y, menos aún, para promover cambios significativos en otros ámbitos de la vida pública y privada. Unido también a las reivindicaciones feministas que habían adelantado las mismas mujeres, se inicia el cumplimiento de una serie de conferencias, resoluciones, convenios y acuerdos mundiales en beneficios del desarrollo de la mujer, que hasta este momento cobraban sentido y valor (OIT, 2004, p.7).

En este mismo orden, la ONU decidió declarar 1975 como el Año Internacional de la Mujer y convocar a una serie de conferencias para comprometer a los Estados a adoptar estrategias y planes de acción para mejorar la condición social de las mujeres.

A la fecha, el interés de la ONU en este tema, lo ha corroborado en la movilización mundial de Estados y sociedad civil en 
el cumplimiento de cuatro conferencias internacionales sobre el tema de las mujeres (México, 1975; Copenhague, 1980; Nairobi, 1985, y Beijing, 1995) y dos reuniones de seguimiento de la última conferencia (Nueva York, 2000 y 2005). En la misma medida se han realizado encuentros en distintas temáticas, que si no directamente, en puntos separados han contribuido al progreso de la inclusión de lo femenino en acciones reales; de ellos destacamos: la Cumbre Mundial sobre Medio Ambiente y Desarrollo (Río de Janeiro, 1992), la Conferencia Mundial de Derechos Humanos (Viena, 1993), la Conferencia Mundial sobre Población y Desarrollo (El Cairo, 1994), la Cumbre Mundial sobre Desarrollo Social (Copenhague, 1995), lo mismo que la declaración del Milenio de las Naciones Unidas (2000), y la Cumbre sobre Financiación para el Desarrollo (ONU Mujeres, 2016).

Finalmente, en complementariedad a los logros jurídicos, es necesario que en el plano del mundo de vida se transformará la condición social, económica y política de las mujeres y que reflejara sus verdaderas preocupaciones. Es lo que se detalla en cada una de las conferencias mundiales dedicadas a la mujer, que por primera vez se constituía en una oportunidad de diálogo a partir de las limitaciones que evidenciaba la mujer en relación a la desigualdad y diferencia en temas fundamentales como la discriminación, la participación política, la salud, la educación, la violencia, la explotación sexual, entre otras.

\section{De la Revolución Francesa (1789) a la liberación femenina (1960)}

Los conflictos en torno al género y el poder, han sido un componente fundamental en la historia del mundo moderno. Esto es tan válido para Europa, Norteamérica como para los países en desarrollo donde estos conflictos -en la temática de género, la 
nación y la clase social- han sido con frecuencia muy intensos (Molyneux, 2003, p.7). Universalmente la mujer ha tenido una participación contundente en los procesos sociales, donde a través de su movilidad social ha favorecido su visibilización para luego obtener su integración y a su vez lograr transformar lo que culturalmente ha sido desvirtuado con la sola presencia suficiente de lo masculino en temas como la participación política, educación, aspecto sociocultural, entre otros.

La historia contemporánea ejemplifica de tres maneras la preponderante participación de movimientos de mujeres a nivel mundial, que preceden la movilización y la participación activa de las mujeres en América Latina. Se destacan entonces en 1789 en París, la jornada del 5 de octubre que empieza con una manifestación de mujeres, el cortejo de mujeres en número de 5 o 10 mil decidieron marchar sobre Versalles. Luego en New York, el 8 de marzo de 1908, mujeres estadounidenses organizan una marcha en sus calles, para conmemorar las protestas de 1857 de las trabajadoras de la industria de tejido. De igual manera, la Revolución Rusa la iniciaron las mujeres en 1917 cuando las obreras textiles salieron a la huelga en Petrogrado y llamaron a todos los trabajadores a apoyarlas. Sus consignas eran por mayores salarios, contra la autocracia y contra la guerra (CEPAL, 1989, p.5). Sumado todo esto a la movilidad que produjo la obtención de la ciudadanía iniciando en países estadounidenses y europeos para el derecho al sufragio y obtener la inclusión educativa, que posteriormente buscaría efectos de participación activa en los procesos políticos, donde se han establecido en torno al tema de género y especialmente de la mujer.

Las contrariedades de la mujer contra la dominación patriarcal tiene sus orígenes en el siglo XVIII; existe para la época una 
consolidación colectiva de la mujer que pretende restablecer la igualdad de sus derechos y la reconstrucción de su identidad, incorporándose una lucha social y política, que se cristaliza en el movimiento sufragista. Son los inicios del movimiento feminista en sí, que se consolida hasta finales de la década de 1960 (Javaloy, 2001, p.346).

En este sentido, las reivindicaciones feministas, van dirigidas en contra de la subordinación o sistema de dominación masculina, a partir de la autoridad del hombre en la familia, generaliza y justifica su dominio en todas las esferas de la vida social, como la economía, la política, el derecho y la cultura. Las ventajas que obtuvo el hombre no fueron de tipo práctico e instrumental, como las ya citadas, sino también de tipo psicológico, ya que al convertirse en el protagonista de la vida social, se sintió superior a la mujer, lo cual reforzó su autoestima y su orgullo de ser hombre. Todo a costa de hacer de la mujer un personaje secundario y dejarla, por sí misma, en desventaja.

De esa manera, en el clima de libertad, igualdad y fraternidad, creado por la Revolución Francesa, aparecieron algunas obras en $1792^{2}$ que se convirtió en la obra clásica del feminismo; su argumentación es que las mujeres nacen como seres humanos pero la educación las convierte en femeninas y subordinadas al hombre; propone la educación igual para los hombres y mujeres como correctivo. En ese ámbito, voces femeninas encarnadas en Olympe de Gouges, la responsable de establecer en paralelo una Declaración de los derechos de la mujer y de la ciudadanía, fueron intentos fallidos. Solo logró que la guillotinaran.

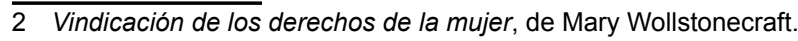


Más adelante, continúa la insistencia por la visibilidad, donde movimientos sufragistas, tienen logros concretos ya en el siglo XIX, específicamente en Gran Bretaña. En 1866 el político y filósofo John Stuart Mill presenta al parlamento una petición firmada por 1.500 mujeres, que reclamaban el derecho al voto que aunque fue desestimada permitió, un año después, la fundación de la Sociedad Nacional de Sufragistas, a favor de sufragio de la mujer. Sería a finales de este siglo en ese mismo país donde la mujer obtuviera el derecho a votar por vez primera. Luego seguirían países europeos, anglosajones y de Latinoamérica (1929).

Sin embargo, es en la década de 1960, donde mayoritariamente estaban establecidos los derechos del voto para la mujer, y el favorable clima cultural de la época, lo que permitió que se resaltaran dos fenómenos relacionados con el feminismo: la revolución cultural que incluye una revolución sexual, y la eclosión de los nuevos movimientos sociales en los que participaban las mujeres. Sustancialmente en la década de los sesenta, en la efervescencia de los movimientos sociales no solo de mujeres, se abre paso desde la investigación un cambio profundo en cuanto a la productividad y orientación, en el panorama del comportamiento colectivo. De esta manera en una capitulación hecha en el año 1975 sobre el estado del campo, se constató el aumento espectacular en literatura en el comportamiento colectivo y movimientos sociales, notándose tan solo en el período 1969-1975 más del doble de los libros especializados en el área que en los 25 años anteriores (Javaloy, 2001, p.4).

En resumen, la línea de tiempo definida entre 1789 hasta 1960, es donde se encuentran definiciones favorables para la mujer, siendo el punto inicial la propia autodesignación de la mujer en búsqueda de sus reivindicaciones, época que marca tras- 
cendencia cuando ya en la década de los setenta hay nuevos derroteros cuando la comunidad internacional centra su atención en el tema de género a partir de decenio de las Naciones Unidas para la mujer en 1975 y las conferencias que se amplían hasta el año 1995.

\section{Movimientos de mujeres latinoamericanas (1929)}

En América Latina la movilidad de las mujeres no solamente estuvo en torno al sufragio y a la ideología feminista; además ha habido reivindicaciones en cuanto a los derechos humanos, la etnia y la clase. Lo anterior, en virtud a que de acuerdo a la pertenencia de esta última, surgían las necesidades de buscar la visibilidad para una mejor existencia. En América Latina ha existido una amplia movilización social por parte de las mujeres, aun de la poca participación política; porque la extensión de lo ideológico requiere de unos compromisos políticos, para que existan transformaciones a partir de qué motiva la movilización. Ha existido participación en todas las modalidades, independientemente de la clase, grupo social, condición de vida, varía según la situación económica, como a su vez el poder que en conjunto maneja la educación, las tradiciones culturales y la ideología.

De manera tal, que las reivindicaciones de la mujer en torno a la etnia y a la clase, ejemplificadas en las mujeres de clase alta, la movilización en relación al sufragio tiene que ver con la defensa de su interés y privilegios; la participación de las pertenecientes al nivel medio urbano, depende de su formación académica, medio laboral. En general, el voto es manipulable y su movilidad se da por factores externos. En relación al nivel medio-alto, las mujeres rechazan los cambios y mantienen sus convicciones a través de lo acordado con sus cónyuges; es algo parecido a las que pertenecen al nivel medio-bajo, que se orientan por la ideo- 
logía de consumo y su voto es manipulable por sus parejas o familiares. Por último, la perteneciente al nivel popular, se movilizan por acciones de hecho y movimientos espontáneos (CEPAL, 1989, pp.13-15). De lo anterior, podemos anotar que ha existido participación, que en los dos extremos en el nivel alto y el popular existen motivaciones más propias y concretas, lo que a diferencia de los otros niveles depende de situaciones externas y hay manipulación en las decisiones a participar.

En una lógica equivocada, se suele creer que las mujeres latinoamericanas estuvieron muy retrasadas respecto de las europeas y estadounidenses en la consecución del derecho al voto o de otras reivindicaciones liberales y democráticas. Pero esto no fue así, y, podemos realizar una breve síntesis, primeramente en relación a movilidad en torno a la adquisición del derecho al sufragio y más adelante con movimientos sociales, demandantes de situaciones de derechos humanos, laborales, libertarios y asociación, entre otros.

En cuanto a la movilidad de las mujeres en la obtención de derechos civiles, especialmente a elegir, destacamos en México en el año 1870 a la poetisa y maestra mexicana Rita Cetina Gutiérrez quien fundó La Siempreviva, un grupo sufragista en Yucatán, compuesto fundamentalmente por maestras que teorizaban sobre la educación y, en especial, la educación de las mujeres. Sabemos también que entre 1910 y 1915, ocho estudiantes de la Escuela de Derecho de Mérida presentaron su tesis sobre el tema del divorcio y los derechos de las mujeres. Con estos antecedentes se convocó en Mérida a los dos primeros congresos feministas de la historia de México, en enero y noviembre de 1916. En ellos las delegadas apoyaron el derecho al voto y la participación política de las mujeres, divulgaron informaciones 
sobre anticonceptivos y abortivos, se pronunciaron a favor de la educación laica, exigieron el fin del fanatismo, la intolerancia y la superstición religiosa. En las elecciones de 1923, el Partido Socialista de Yucatán obtuvo tres diputadas mujeres y una suplente.

En el albor de 1880, organizaciones femeninas en Brasil conformaron asociaciones abolicionistas de la esclavitud. En 1910, en Argentina se realizó el Primer Congreso Feminista Internacional, con delegadas extranjeras y nacionales, para tratar las mejoras sociales, la lucha por la paz, el acceso femenino a la educación superior y para expresarse en contra de la doble moral. En Colombia, en 1912, se manifestaron a favor de los derechos civiles de la mujer casada. En Panamá, en 1916, fundaron el primer Centro de Cultura Femenina, cuyo lema era "virtud y patria". En Honduras, en 1924, se fundó un Círculo de Cultura Femenina para el estudio con las mujeres de sectores populares; ellas se enfrentaron machete en mano a la intervención militar norteamericana. En Chile, en 1930, se organiza el movimiento en pro de la emancipación de la mujer chilena (Taller feminista, 2013).

Por otro lado, en cuanto a movimientos sociales, en la restitución de derechos humanos tenemos por ejemplo, la experiencia en el año 1977 de las Madres de la Plaza de Mayo en Argentina tiene algunas semejanzas con la conformación del Comité de Madres de El Salvador, consolidado en 1980, más tarde llamado Las Comadres, que a su vez, tiene que ver con la búsqueda de reivindicaciones de derechos humanos en torno a la libertad, cuando algunos de sus familiares en primer, segundo o tercer grado han sido detenidos y/o desaparecidos. En el caso de las Madres de la Plaza de Mayo, cuya emergencia fue el resultado de una coyuntura histórica precisa: el accionar sistemático 
del terrorismo de Estado durante la última dictadura llevó a la organización de las madres con el fin de encontrar a sus hijos secuestrados (Basile, 2001, p.68).

Aunque aún en el siglo $\mathrm{XXI}$, coinciden movimientos como las Damas de Blanco en Cuba, que desde 2003, también levantan sus voces, para fortalecer su molestia contra los setenta y cinco presos políticos por parte del gobierno cubano, al no permitir la libre expresión y libre asociación; al considerar que estas acciones van en contra vía. En ese sentido, la toma de las calles por parte de las Damas de Blanco, implica además, no solo el enfrentamiento por el espacio público en La Habana, sino la lucha por la reconstrucción de una ciudadanía basada en valores diferentes, e incluso contrarios a los promovidos por el Estado cubano. En la época contemporánea, una de las herramientas, que permite mayor visibilidad a las Damas de Blanco de Cuba, es sin duda la plataforma tecnológica que ha permitido que a través de las redes sociales, y mediante la creación interactiva de su blog, puedan mantener comunicación, en relación a su movilidad social dentro, y ya desde el año pasado, fuera de la Habana (Damas de blanco, 2003).

Muy diferente a movimientos de mujeres que en algunos países de América Latina, surgen en torno a reivindicaciones de clase y que se encuentran distanciados de los grupos feministas; encontramos por ejemplo, que a comienzos de siglo en 1905, en Uruguay existían organizaciones de resistencia a los oficios domésticos (planchar, lavar) y se tienen datos de que las costureras llevaron a cabo una huelga. En Chile, en la proximidad de los años setenta, en el gobierno de Salvador Allende, se recuerdan las "caceroladas", las cuales eran manifestaciones femeninas de protesta por la escasez y de alimento y que curiosamente 
se nutrieron de mujeres de clase media y burguesa, que tenían más bien un carácter de oposición a la unidad popular (Luna, 1998, p.3). En esa misma línea se organiza en 1961, el Comité de Amas de Casa de Bolivia del siglo XX, el cual estaba constituido por las esposas de los trabajadores de la mina ubicada a unos 335 kilómetros de la capital boliviana, quienes unieron para visibilizar la problemática laboral de sus compañeros, que era transversal a sus familias, de lo que subyacía la difícil situación precaria que experimentaban para la época (Viezzer, 1968, pp.76-77).

En síntesis, la contribución de los diferentes ideales que dieron paso al asocio de mujeres en América Latina ya sea por el sufragio, feminismo, derechos humanos y clase, son de vital importancia, porque en conjunto han permitido una búsqueda de visibilidad que permite mayor presencia, como también, darle solución a las diferentes demandas que tenían las mujeres en las diferentes épocas. Luego en la década de los ochenta del siglo XX, desde el retorno a la democracia en varios países latinoamericanos y paralelamente, desde el agotamiento de modelos de regímenes de partido único (o de sistemas de partido hegemónicos), las mujeres han ganado una mayor visibilidad en el ámbito público. Estos procesos de transición hacia regímenes políticos más competitivos y pluralistas, han dado lugar a demandas de una mayor inclusión femenina en la toma de decisiones y a ciertas reivindicaciones vinculadas con el logro de un tratamiento (o trato) igual entre hombres y mujeres. (CEPAL, 2011, p.11). Se evidencia lo anterior, en la participación social de la mujer como un avance cuando a finales de la década de los ochenta y principio de los noventa, países como Argentina (1995), Brasil (1988), Colombia (1991), Ecuador (1998), Paraguay (1992) y Perú (2000), convocaron a participar la represen- 
tación femenina en la elaboración de Constituciones de estos países, donde ha quedado reflejada no solo la incorporación de propuestas de inclusión de la convención para la eliminación de todas las formas de discriminación contra la mujer (CEDAW), y leyes de afirmación positiva, sino la inclusión de debates públicos en temas considerados hasta entonces de índole privada, que debilitaban las fronteras entre los espacios públicos y privados (CEPAL, 2003, p.19).

\section{Proceso de participación y movilización de la mujer en Colombia}

Los movimientos sociales en Colombia surgieron hacia finales del siglo XIX y comienzos del XX, como parte y reacción de los cambios estructurales a nivel económico que se estaban desarrollando en el país. Estos provocaron una transformación de las actividades productivas y de los modos de organización rural y urbana. A su vez, generaron tensión en las relaciones laborales, lo que derivó en la formación de organizaciones laborales y campesinas. Estas exigían salarios justos, mejores condiciones de trabajo, tierra para trabajar, entre otras peticiones, que buscaban mejorar la calidad de vida de los trabajadores.

En los años veinte, con el crecimiento de la economía colombiana, se produjeron migraciones masivas del campo a la ciudad -para los campesinos era la única opción de subsistencia-, por lo tanto se aceleró la urbanización, la construcción de obras públicas, creció el empleo y, como consecuencia directa, los trabajadores comenzaron a asociarse exigiendo mejores condiciones laborales.

En pleno fulgor de los años cincuenta, la situación de guerra interna y el lugar que toma en los últimos años por el alto nivel 
de degradación de la confrontación armada, es factor decisivo en los procesos organizativos de los movimientos sociales y de mujeres. Los efectos de la guerra en la población en general y en las mujeres en particular, va a reorientar dramáticamente las acciones de los grupos que, contando con recursos de la cooperación internacional, favorecen intervenciones de carácter humanitario, de emergencia, sobre afectados y víctimas. En tales condiciones, un número importante de organizaciones del movimiento volcarán sus esfuerzos hacia la denuncia de vulneración de derechos, así como a exigir y proponer salidas negociadas al conflicto armado colombiano. Igualmente, a dedicar su trabajo directo a atender mujeres, hombres y familias en condiciones de desplazamiento forzado (Lamus, 2009, p.129).

Dentro de esa línea de movimientos sociales en este país, el protagonismo femenino lleva siempre implícito el cuestionamiento del orden social existente, en particular el orden de género que rige el conjunto de relaciones de mujeres y hombres en la vida doméstica y en la vida pública. Tal cuestionamiento ha sido y sigue siendo la base de las transformaciones que lenta y conflictivamente, adelantan las mujeres para establecer en la sociedad un orden en el cual los conceptos de equidad y democracia sean una realidad en la vida cotidiana (Velazquez, 1995, p.5).

La primacía de los movimientos de mujeres adscritas a corrientes feministas se han destacado en el país desarrollando acciones, en relación a la vida laboral, derechos humanos, la participación, la salud sexual y reproductiva, entre otros. Signos de movimientos en la década de 1920, mujeres que organizaron una huelga de obreras en Fabricato, empresa ubicada en el departamento de Antioquia, logró el $40 \%$ del aumento de salarios, contrastado casi para la misma fecha (1927), con un 
manifiesto firmado por 14.000 mujeres indígenas, en la búsqueda de sus derechos (Luna, 1998, p.3).

Ya para la época de 1975 a 1982, la cual se identifica por un matiz denominado, como del auge de la "utopía feminista", no representaba una sólida acumulación de experiencias y reflexiones que impactaran el quehacer académico. En cambio, el período fue notable por el surgimiento de muchos grupos y centros feministas, la desaparición de otros tantos y el ahondamiento de los debates y divisiones en torno al tema de la autonomía del movimiento feminista, frente a la militancia partidista (León, en Barrera, 2007, p.41).

En 1977 se propició un debate importante al interior de los partidos políticos. Surgieron en Bogotá grupos que -incluyendo a militantes- discutieron coordinadamente. Algunas socialistas se retiraron de su partido, planteando la necesidad de autonomía de la organización de las mujeres, criticando el verticalismo de los partidos y organizaciones políticas y cuestionando la división sexual del trabajo en ellas. El proceso se detuvo, pero nacieron agrupaciones que continuaron la reflexión y la difusión de sus planteamientos. Otros grupos se crearon en Barranquilla, Cartagena, Pasto, Bucaramanga, Ibagué, Montería, Ovejas, Cali y Medellín. En diciembre de 1978 se realizó un encuentro nacional de mujeres que discutió el tema de la sexualidad y la participación en la campaña internacional: "Por el derecho al aborto, a la contracepción y contra las esterilizaciones forzadas: las mujeres deciden". Esta campaña dio origen a innumerables actividades, entre ellas una marcha exigiendo el derecho al aborto (Barrera, 2007, p.40).

Dentro de las movilidades de los diferentes grupos de muje- 
res, se organiza en Bogotá en julio de 1981, el primer Encuentro Feminista Latinoamericano y del Caribe, organizado por los grupos feministas colombianos. Abordan temáticas, que hasta esa época eran consideradas un tabú y se dio paso a las discusiones sobre la doble militancia -política y feminista-, la sexualidad, el aborto, la opción sexual y la lucha de clases, temas que ocuparon un lugar privilegiado y avanzaron hacia una reflexión más sistemática en lo teórico, lo estratégico y lo organizativo. Para las feministas colombianas marcó la seguridad de que era posible proyectarse a otros sectores de mujeres y de la sociedad. Surgieron los primeros centros de mujeres en Cali, Medellín y Bogotá, dedicados a producir información, prestar servicios legales, médicos, centros de documentación, publicaciones, etc. (Barrera, 2007, p.40).

En 1984 los grupos feministas de Bogotá participaron activamente en la convocatoria al Diálogo Nacional y la Apertura Democrática, conscientes de que era necesario dar un contenido, desde las mujeres, a los diálogos que se iniciaban con sectores de la guerrilla colombiana. El proceso de debate y reflexión entre los grupos feministas posibilitó ese año la creación del Colectivo de Mujeres de Bogotá.

En 1988, ante la convocatoria del gobierno a un debate para reformar la Constitución, la Casa de la Mujer, de Bogotá, y el Colectivo de Mujeres se integran a las mesas de trabajo Por la Paz y la Reconciliación Nacional. Ese mismo año, 17 grupos de mujeres elaboran una propuesta de Reforma Constitucional que incluía el reconocimiento de las mujeres como ciudadanas con plenos derechos -sociales y humanos-, la modernización de las instituciones sociales y políticas, además, la eliminación del Concordato entre el Estado de Colombia y la Santa Sede 
en las elecciones de la Asamblea Nacional Constituyente, en el cual el movimiento feminista participó con una lista de mujeres. Fue una notable experiencia de aprendizaje político, donde se hicieron visibles potencialidades y debilidades (Páez, en Barerra, 2007, p.42).

Finalmente, en Colombia, no hay duda, que es en el contexto de la industrialización donde se ven aparecer las mujeres reivindicando sus derechos; aunque en los años 40, cuando estaba el movimiento en su lucha más intensa, no se logró el derecho al sufragio, sino que fue en la década de los 50 , específicamente en el año de 1954, bajo el gobierno en dictadura de Gustavo Rojas Pinilla (Luna, 1998, p.4).

\section{Mujeres votantes colombianas (1954)}

Aunque en América Latina, fue Ecuador el primer país donde se dio paso por primera vez al voto femenino en 1929; en Colombia, en este sentido, la femineidad se resignificó con la modernidad, aunque se puede considerar una construcción de la cultura occidental desde siglos atrás, con una acumulación de significados procedentes de la filosofía clásica y de las concesiones de la iglesia sobre las mujeres.

La Asamblea Nacional Constituyente de 1954 aprobó el derecho femenino al voto: ratificado por el Plebiscito de 1957, convocado por la alianza liberal conservadora que sustentó la forma reconciliadora del Frente Nacional. En este cuarto de siglo, durante el que las sufragistas no dejaron de luchar de una u otra forma, se han distinguido tres sub-períodos (Luna, 1998, p.4).

La antecede el primer sub-período (1930-1943), en el que las 
mujeres habían obtenido sucesivamente la administración de los propios bienes, el acceso a la Universidad y a cargos públicos -logros que beneficiaron a mujeres de clase media y alta- pero se había perdido, en sucesivos debates parlamentarios, la pelea por el sufragio. La modernización social llevada a cabo por los liberales quedó incompleta en este punto.

Entretanto, se había comenzado a formar una corriente política de mujeres que recibía las influencias de la experiencia acumulada por la corriente internacional sufragista y que estaba en estrecha relación con núcleos liberales y socialistas. Paralelamente, se formó otra corriente de mujeres que defendió con ahínco las visiones conservadoras de la feminidad, alimentadas en buena parte por la reacción en ese sentido que se produjo en la Europa nazi y fascista frente a los avances del sufragismo (Luna, 1999, p.195).

En Colombia se pueden contabilizar once proyectos de ley a favor del sufragio femenino entre 1933 y 1954. En 1954, fue finalmente aprobado el derecho de las mujeres al voto por la Asamblea Constituyente, institución convocada por el presidente Gustavo Rojas Pinilla. A lo largo de los años hubo muchos debates en las Cámaras y en la prensa (Luna, 1999, p.201).

Durante la discusión de uno de los muchos proyectos de ley sobre el sufragio femenino, doce miembros del Senado opinaban en la prensa sobre el voto y once lo hacían en contra, con igual argumento: la mujer tiene un vasto campo en el hogar para desarrollarse como persona, mientras la política es la más "vergonzosa de nuestras actividades". Pero iban más allá: el voto femenino es "peligroso para el régimen", porque es "contrario a la realidad nacional", porque "volveremos a tener a los obispos 
de virreyes", porque "es odioso ver a las mujeres en la política", porque "puede llegar a menoscabar su tranquilidad" (la de la mujer), porque "no está preparada para dar este salto", porque "no corresponde a un anhelo de la mujer", porque "la mujer latina tiene más disposición para el hogar que para la urna", etc. Junto a estos once senadores contrarios, uno solo se declaraba partidario del voto; argumentaba que "con ello se inicia la campaña para nivelar la actual inferioridad económica y social de la mujer". Al lado de la defensa del voto femenino fundamentada en la justicia y la igualdad, aparecen las oposiciones del hogar (significando tranquilidad, aptitud latina, limpieza) (Luna, 2000).

En definitiva, las sufragistas colombianas en general, pondrán en cuestión la ausencia en la sociedad como ciudadanas, la au128 sencia de su voz, su voto, su participación en la vida política, pero fue un proceso de décadas en el logro de sus demandas (Luna, 1998, p.5).

\section{De la participación activa a la representación}

La representación política de lo femenino, sigue siendo el desafío pendiente. Aunque en lo educativo hay unas proximidades estadísticas a los niveles paritarios, no ocurre igual para la participación directa en cargos de elección popular o de decisiones de política pública, que puede influir mayormente en los progresos de la inserción de la mujer, en los distintos espacios de la vida pública. En este sentido se presentan a continuación, los retos y desafíos de los organismos internacionales y nacionales (Colombia), en relación a la búsqueda paritaria de la representación política de la mujer que se fortalecieron desde que la ONU a través de las conferencias mundiales desde 1975, inicia la visibilización de la mujer. 


\section{Avances y desafíos en las cuatro conferencias de la mujer (ONU 1975-1995)}

En el mismo año en que la ONU había declarado el Año Internacional de la Mujer de las Naciones Unidas, se dio origen al mandato por el cual la Asamblea General proclamó al período 1975-1985 como el Decenio de las Naciones Unidas para la Mujer, como a su vez el inicio de la primera conferencia mundial sobre la Mujer en México en el año 1975. Transcurría la guerra fría y en América Latina existían países con regímenes no democráticos (Chile, Argentina), algunos con problemas de guerrillas (Colombia, Perú). Ya para la década de los ochenta y noventa (Conferencias de Copenhague, 1980 y Nairobi, 1985) se llevaron a cabo profundas reformas al rol del estado en la economía impulsadas por los programas de ajuste estructural, las reformas de segunda generación, la orientación del comercio hacia la exportación y la promoción de la inversión extranjera directa. Paralelamente, se llevaron a cabo procesos de democratización en la mayoría de los países del mundo, dejando atrás la generalidad de las viejas dictaduras.

En el caso de muchos países de América Latina, las medidas de liberalización económica se dieron de manera paralela a la caída de varias dictaduras, impulsando de esta forma procesos de elección más democráticos. En suma, se dio un proceso de liberalización política, económica, comercial, social y cultural, que terminó por consolidar los procesos de globalización ya en ciernes, en los cuales se observa un proceso creciente de interacción entre naciones y países en todo ámbito de la vida: social, cultural, comercial, financiero, administrativo, religioso y hasta político (OIT, 2004, p.27).

Antes de la Conferencia de México, las políticas públicas para las mujeres estaban dirigidas a su rol como madres, ya que sus tareas reproductoras eran consideradas la contribución más im- 
portante. Las necesidades que se le reconocían a las mujeres, estaban vinculadas particularmente con la alimentación, la desnutrición infantil y la planificación familiar.

En este contexto, las mujeres eran observadas como beneficiarias pasivas, tanto por los gobiernos, como por las ONG y el sector privado. En México, por primera vez se insta a los gobiernos para que reúnan información estadística sobre la situación de las mujeres, como también se analiza la condición jurídica y social de la mujer como preámbulo del decenio de 1976 a 1985 que es dedicado a la mujer por la ONU; en esta conferencia se establecieron tres fundamentales:

- La igualdad plena de género y la eliminación de discriminación;

- La integración y plena participación de la mujer en el desarrollo;

- La contribución cada vez mayor de la mujer en el fortalecimiento de la paz mundial.

Buscaban, una aproximación sobre la igualdad entre los géneros, que contribuyera a mejores oportunidades en empleo, educación, participación política. Este encuentro quedó refrendado por las 133 delegaciones de Estados miembros de todo el mundo; las comisiones estaban representadas por 113 mujeres, un porcentaje significativo para la época. En este espacio se logran consolidar el Instituto Nacional para la investigación y capacitación para la promoción de la mujer (INSTRAW) y El fondo de desarrollo para las Naciones (UNIFEN), lo cual conforma un marco institucional para la investigación y las actividades operacionales de la mujer y su desarrollo (ONU Mujeres, 2011, p.144). 
La segunda conferencia desarrollada en Copenhague, comenzó con un proceso de evaluación de la primera conferencia, realizada en México. Uno de los logros que preceden a esta conferencia es que ya participan 145 Estados miembros, lo que aumentaba en 12 de los participantes en el primer encuentro y también que en 1979 se refrenda por la Asamblea de la ONU la principal convención sobre los derechos de las mujeres, que estipula las obligaciones legales internacionales de los Estados, consolidándose la CEDAW para prevenir todas las formas de discriminación contra las mujeres. Es el único instrumento de derecho internacional que reconoce claramente la necesidad de comprender la violación de los derechos de las mujeres tanto en la esfera pública como en la esfera privada (Internacional, 2012).

Ahora bien, las discusiones de esta conferencia se orientaban a analizar los límites que tenía la mujer en los espacios sociales, de la siguiente manera:

- Disparidad entre los derechos garantizados y la capacidad de la mujer para ejercer sus derechos;

- Igualdad en el acceso a la educación;

- Oportunidad de empleos;

- Servicios adecuados de atención en salud.

Para superar todas estas dificultades de la participación de la mujer en el ejercicio pleno de sus derechos, se propuso que los hombres estuvieran inmersos en el mejoramiento del rol de la mujer, como a su vez que la voluntad política favoreciera los espacios para el reconocimiento de las contribuciones de la mujer a la sociedad, y en definitiva, aumentara los recursos financieros para la integración de la mujer en la vida nacional.

Tras las revisión del cumplimiento o no de las medidas adop- 
tadas en Copenhague, se da inicio a la tercera conferencia realizada en Nairobi en 1985, con la asistencia de 157 Estados miembros; y se constata el empeoramiento progresivo de las condiciones de vida de las mujeres, sus dificultades de acceso a la educación, la salud y aumento en la pobreza; se identifican también los principales obstáculos que dificultan la igualdad y el progreso de las mujeres. Se proponen entonces los puntos a desarrollar, los cuales son:

- Medidas constitucionales y jurídicas;

- Igualdad en la participación social;

- Igualdad en la participación política y en la adopción de decisiones.

Dentro de la plataforma de acción se integró el desarrollo de mayores acciones en el fomento de empleo, mayor accesibilidad a la salud, la educación y los servicios sociales incluyendo la industria, la ciencia, las comunicaciones y el medioambiente (ONU, 2012).

Seguidamente, la cuarta y última conferencia tiene lugar en Beijing en 1995; significó un avance tanto cuantitativo como cualitativo al participar 189 delegaciones; a partir del concepto de género, se reconoció que toda la estructura de la sociedad y todas las relaciones entre hombres y mujeres en el interior de esa estructura, tenían que ser reevaluadas. Por lo tanto fue indispensable integrarlo trasversalmente en la política pública, entendiendo que los derechos de la mujer son derechos humanos y que la igualdad entre los géneros era una cuestión de interés universal y de beneficio para todos. Se establece la plataforma de acción, encaminada hacia el logro de doce puntos que tienen como común denominador a la mujer, siendo ellos: 
La pobreza, la educación y la capacitación, la salud, la violencia, conflicto armado, la economía, participación en el poder, la adopción de decisiones, los mecanismo institucionales para el adelanto de la mujer, los medios de comunicación, el medioambiente y la niña.

A modo de cierre de este segmento la plataforma de la conferencia de Beijing constituye el primer compromiso mundial de incorporación de una perspectiva de género como metodología para lograr el empoderamiento de la mujer. Al ponerse en práctica, las medidas sugeridas "deberían promover una política activa y visible de integración de una perspectiva de género en todas las políticas y programas, a fin de que se analicen, antes de adoptar decisiones, sus posibles efectos en las mujeres y los hombres" (PNUD, 2008, p.5).

\section{Análisis antes y después de la conferencia de Beijing}

Considerablemente la última conferencia Mundial de la Mujer, ha cobrado sentido en el compromiso adquirido de más de 180 Estados miembros de la ONU, los cuales iniciaron acciones que si no han eliminado del todo las desigualdades en relación a lo masculino/femenino, hay avances en miras a seguir proyectando la labor (ver Tabla 1).

Uno de los aspectos a destacar es la participación en aumento de los Estados miembros en cada una de las Conferencias (México, 133; Copenhague, 145; Nairobi, 157 y Beijing, 189 países). Lo que significa que entre el primero y el último encuentro mundial, la adscripción de países se aproxima a 50; de igual forma, paralelamente a las conferencias gubernamentales se organizaron otras reuniones convocadas por organizaciones de la sociedad civil, con el objetivo de influir en los temas a debate, en 
ESTUDIOS DOCTORALES FEMENINOS:

Aportes desde las Ciencias Sociales y Humanas

Tabla 1

Síntesis: cuatro conferencias mundiales sobre la mujer

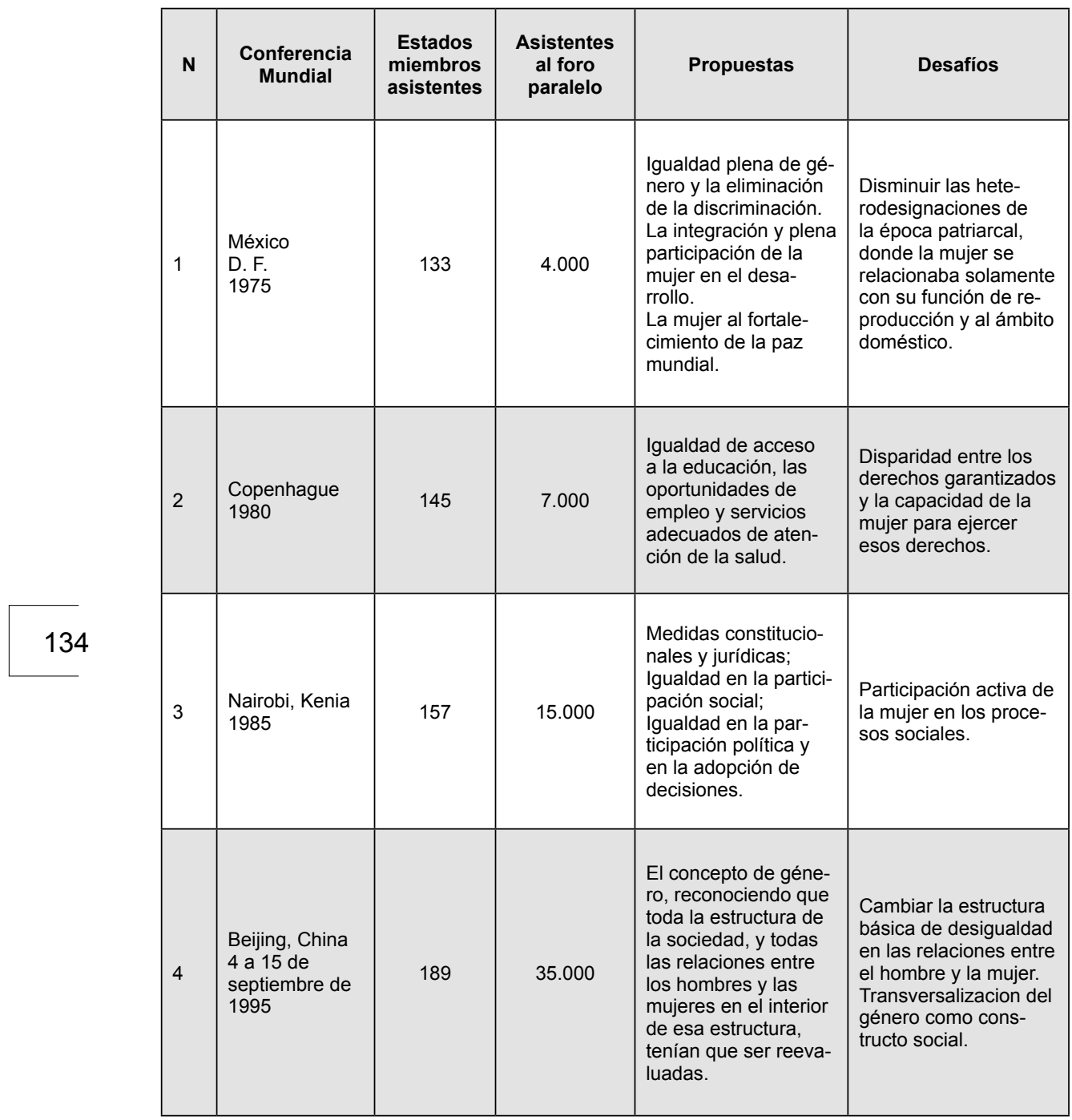

Fuente: Adaptación a partir del análisis de cada una de las conferencias, organizadas por la ONU 1975-1995

las conclusiones de las conferencias y en los tratados y convenciones internacionales. Esos encuentros han servido también para entablar un diálogo entre dichas organizaciones y para crear o extender redes comprometidas con el tema de las mujeres (OIT, 2004, p.8), para lo cual la asistencia fue concurrida con 
$4.000,7.000,15.000$ y 35.000 personas para la primera, la segunda, la tercera y la cuarta conferencia mundial respectivamente. De manera tal que para los Estados miembros, la presencia de la sociedad civil organizada a través de los movimientos de mujeres, son quienes de alguna manera u otra han presentado sus demandas, solicitudes y reclamos; mediante acciones que van desde la presión hasta el cabildeo, la presentación de propuestas y la negociación. De hecho, la visión vanguardista de los movimientos de mujeres contribuyó significativamente al avance de las Conferencias.

Otro logro significativo, es la comprensión de la noción de "género y desarrollo". "Género" es una categoría de análisis de las ciencias sociales que había sido instalada por la teoría feminista, en los años setenta, para describir las características de los hombres y las mujeres que son determinadas y construidas socialmente. Del concepto de género surge lo que hoy se conoce como "la perspectiva de género", que es una herramienta que nos ayuda a comprender cómo estas construcciones adjudicadas a lo femenino y a lo masculino afectan o impactan determinados procesos. Al analizar las diferencias existentes, en las construcciones sociales adjudicadas a lo femenino y a lo masculino y la relación que establecen entre ellos, podemos ubicar problemas de una manera más eficaz (OIT, 2004, p.32). De allí que se potencialice a partir de la conferencia de Beijing, la transversalización del género y se inste a los gobiernos hacerlos parte de la política pública a nivel mundial.

Antes y después de la conferencia de Beijing, se desarrollaron otros encuentros propiciados por la ONU que aunaron los esfuerzos para avanzar, en la construcción igualitaria, que beneficiara a la mujer, permitiendo un mejor desarrollo a nivel relacional tanto en lo público como lo privado destacándose antes de Beijing, la celebración de la Cumbre Mundial de Medioambiente 
y Desarrollo, en Río de Janeiro (1992); la Conferencia Mundial de Derechos Humanos, en Viena (1993); la Conferencia Mundial sobre Población y Desarrollo, en El Cairo; (1994) y la Cumbre Mundial de desarrollo social, en Copenhague (1995).

De la cumbre de Río de Janeiro en 1992 la ONU ha adoptado medidas para integrar el concepto de desarrollo sostenible en todas las políticas y programas pertinentes; se advirtió que tanto el desarrollo económico y social, como la protección del medioambiente son elementos necesarios e interdependientes del desarrollo sustentable. Señala a su vez, que se debe asegurar a los pobres, en particular a las mujeres. En los proyectos de generación de ingresos, se tienen en cuenta sus posibles repercusiones ambientales y va en aumento el número de programas de asistencia para el desarrollo dirigidos a las mujeres. Dando cuenta además, la función esencial que desempeñan como productoras de bienes, servicios y alimentos, como también personas que cuidan del medioambiente (ONU, 1992, p.1).

Ya en el año 1993, la Conferencia de Derechos Humanos realizada en Viena también integra como tema importante a la mujer, reconociendo los derechos de las mujeres y las niñas como parte inalienable, integrante e indivisible de los derechos humanos fundamentales y, como parte de ello, consideró a la violencia contra las mujeres como una violación de sus derechos humanos. Este enfoque integral fue considerado uno de los mayores logros del movimiento de mujeres durante este encuentro. Bajo el lema: "los derechos de las mujeres son derechos humanos", se logró integrar el concepto de que existe una especificidad propia en los derechos de las mujeres, misma que se desprende de la problemática de género que viven para acceder con plenitud a disfrutarlos. Lo anterior implicó un análisis profundo de cómo en muchos países y culturas, solo por ser mujeres, se les niega el acceso a tener un nombre, una nacionalidad, acceder 
a la escuela, decidir sobre su propio cuerpo, votar y ser electas, etc., mientras que los hombres pueden gozar y disfrutar de dichos derechos en el mismo país. Por esta razón, el logro principal de Viena fue que se reconociera la especificidad de género en los derechos humanos (ONU, 1993, p.1).

En el mismo orden, la conferencia realizada sobre la población y desarrollo, en 1993 en El Cairo, busca promover la equidad e igualdad de los sexos, como también los derechos de la mujer. Es el deseo de la eliminación de la violencia de cualquier tipo contra la mujer, como asegurarse de que sea ella quien controle su propia fecundidad, siendo estos la piedra angular de los programas de población y desarrollo. Se considera que los derechos humanos de la mujer y de las niñas son parte inalienable, integral e indivisible de los derechos humanos universales. En ese sentido, la plena participación de la mujer, en condiciones de desigualdad, en la vida civil, cultural, económica, política y social, tanto en el nivel nacional, regional e internacional, sumado a la erradicación de todas las formas de discriminación, por motivos de sexo son prioritarios de la comunidad internacional (ONU, 1994, p.10).

En la cumbre mundial sobre desarrollo social llevada a cabo en Copenhague en el año 1995, se acordó "que no se puede lograr un desarrollo social y económico sostenible sin la plena participación de la mujer, que además, la igualdad y la equidad entre la mujer y el hombre constituye una prioridad para la comunidad internacional. Como tal, debe ser un elemento fundamental del desarrollo tanto económico como social; por lo tanto se promueve la manera de aumentar su participación en la función directiva de la mujer, en la vida política, civil, económica, social y cultural, y en el desarrollo". 
Los tres encuentros que preceden a Beijing, son importantes para los logros que se obtienen allí, debido a que los compromisos adquiridos confluyen a que la mujer debe participar de manera activa en la toma de decisiones y en esta medida se concretan en la plataforma de acciones que se plantean y la transversalización de este tema en todos los escenarios de la sociedad, tanto públicos como privados.

Posteriormente de Beijing, en el nuevo mileno se han desarrollado dos encuentros para evaluar los resultados de esta, los cuales han tenido lugar en New York en 2000 y 2005 denominadas Beijing+5: Mujer 2000 y Beijing+10: revisión después de 10 años (Armentia, 2007, p.84); hacen análisis de los compromisos pactados en la plataforma de acción por cada uno de los países, renovando los compromisos adquiridos y haciendo énfasis en los progresos, incluyendo las deficiencias. Los cambios han sido lentos y aún hay mucho por hacer. Los puntos analizados fueron el de la salud y la violencia contra la mujer. Se tomaron medidas concretas para combatir la violación de los derechos humanos con la creación de campañas contra la violencia, la penalización de la violación (incluyendo al matrimonio), crímenes contra la mujer y la violencia motivada por cuestiones racionales. Se concluyó con la preponderancia de sensibilizar a los funcionarios relacionados con la aplicación de la justicia para que atiendan debidamente a las mujeres víctimas de violencia (OIT, 2004, p.24).

\section{Compromiso de los gobiernos en la transversalización de género después de Beijing}

El compromiso adquirido antes y después de Beijing, en cuanto a refrendar a través de resoluciones, convenios y acuerdos, 
que globalmente las agencias internacionales definen a favor de los derechos de las mujeres, visibilizan temas álgidos como: la participación social y política, la explotación y violencia sexual, en derecho (laboral, humano), conflicto armado, discriminación y matrimonio, lo cual permite, desde el referente internacional, ponerlo de relieve en los niveles intrapaíses, lo que permite mayores abordajes para la integración de la mujer en los distintos segmentos institucionales dejando de lado aquellos limites que han permeado históricamente su confinación al mundo privado y la heterodesignación que aún es una manera de segregación sociocultural. En la siguiente tabla, encontramos detalles de esos documentos, por los niveles enunciados arriba (ver Tabla 2).

\section{Tabla 2}

Selección de resoluciones, convenios internacionales ONU

\begin{tabular}{|c|c|c|}
\hline Tema & Año & Documento \\
\hline \multirow{5}{*}{$\begin{array}{l}\text { Explotación y } \\
\text { violencia sexual }\end{array}$} & 1949 & $\begin{array}{l}\text { Convenio para la represión de la trata de personas y de la explo- } \\
\text { tación de la prostitución ajena. }\end{array}$ \\
\hline & $1994-2010$ & $\begin{array}{l}\text { Resolución de la Asamblea General sobre la trata de mujeres y } \\
\text { niñas. }\end{array}$ \\
\hline & 2000 & $\begin{array}{l}\text { Protocolo para prevenir, reprimir y sancionar la trata de personas, } \\
\text { especialmente mujeres, niñas y niños, que complementa la Con- } \\
\text { vención de las Naciones Unidas contra la delincuencia organizada } \\
\text { transnacional. }\end{array}$ \\
\hline & 2008 & Resolución 1820 del Consejo de Seguridad. \\
\hline & 2009 & Resolución 1888 del Consejo de Seguridad. \\
\hline \multirow[b]{2}{*}{ Matrimonio } & 1957 & Convención sobre la nacionalidad de la mujer casada. \\
\hline & 1962 & $\begin{array}{l}\text { Convención sobre el consentimiento para el matrimonio, la edad } \\
\text { mínima para contraer matrimonio y el registro de los matrimonios. }\end{array}$ \\
\hline \multirow{5}{*}{$\begin{array}{l}\text { Derechos labo- } \\
\text { rales }\end{array}$} & 1951 & $\begin{array}{l}\text { Convenio de la OIT relativo a la igualdad de remuneración entre } \\
\text { la mano de obra masculina y la mano de obra femenina por un } \\
\text { trabajo de igual valor. }\end{array}$ \\
\hline & 1958 & $\begin{array}{l}\text { Convenio de la OIT relativo a la discriminación en materia de em- } \\
\text { pleo y ocupación. }\end{array}$ \\
\hline & 1981 & $\begin{array}{l}\text { Convención de la OIT relativa a la igualdad de oportunidades y de } \\
\text { trato entre trabajadoras y trabajadores: trabajadores con respon- } \\
\text { sabilidades familiares. }\end{array}$ \\
\hline & 2000 & $\begin{array}{l}\text { Convenio de la OIT relativo a la revisión del Convenio sobre la } \\
\text { protección de la maternidad (revisado de 1952). }\end{array}$ \\
\hline & 2009 & $\begin{array}{l}\text { Resolución de la OIT relativa a la igualdad de género como eje } \\
\text { del trabajo decente. }\end{array}$ \\
\hline
\end{tabular}

Tabla 2 (Continúa) 
Tabla 2 (Viene)

\begin{tabular}{|c|c|c|}
\hline \multirow{3}{*}{$\begin{array}{l}\text { Derechos huma- } \\
\text { nos y ruralidad }\end{array}$} & 1993 & Declaración y Programa de Acción de Viena \\
\hline & $1982-2009$ & $\begin{array}{l}\text { Resolución de la Asamblea General, relativa al mejoramiento de } \\
\text { la situación de la mujer en zonas rurales. }\end{array}$ \\
\hline & 1993-2009 & $\begin{array}{l}\text { Resolución de la Asamblea General sobre violencia contra las tra- } \\
\text { bajadoras migrantes. }\end{array}$ \\
\hline \multirow{5}{*}{$\begin{array}{l}\text { Salud sexual y } \\
\text { reproductiva }\end{array}$} & 1994 & $\begin{array}{l}\text { Programa de acción de la Conferencia Internacional sobre la Po- } \\
\text { blación y el Desarrollo. }\end{array}$ \\
\hline & $1997-2001$ & $\begin{array}{l}\text { Resolución de la Asamblea General sobre prácticas tradiciona- } \\
\text { les o consuetudinarias que afectan la salud de las mujeres y las } \\
\text { niñas. }\end{array}$ \\
\hline & $1997-2009$ & $\begin{array}{l}\text { Resolución de la Asamblea General sobre las mujeres en el de- } \\
\text { sarrollo. }\end{array}$ \\
\hline & 2001 & $\begin{array}{l}\text { Declaración de compromiso de la Asamblea General en la lucha } \\
\text { contra el VIH/SIDA. }\end{array}$ \\
\hline & 2009 & $\begin{array}{l}\text { Resolución del Consejo de Derechos Humanos sobre mortalidad } \\
\text { y morbilidad materna prevenible y los derechos humanos. }\end{array}$ \\
\hline \multirow{5}{*}{$\begin{array}{l}\text { Participación de la } \\
\text { mujer en procesos } \\
\text { democráticos }\end{array}$} & 1995 & Declaración y Plataforma de Acción de Beijing. \\
\hline & 1997 & $\begin{array}{l}\text { Resolución de la Asamblea General sobre las mujeres en el de- } \\
\text { sarrollo. }\end{array}$ \\
\hline & 2000 & Declaración del Milenio de las Naciones Unidas. \\
\hline & 2003 & $\begin{array}{l}\text { Resolución de la Asamblea General sobre las mujeres y la parti- } \\
\text { cipación política. }\end{array}$ \\
\hline & 2010 & $\begin{array}{l}\text { Declaración Ministerial del Consejo Económico y Social sobre la } \\
\text { aplicación de compromisos internacionales relativos a la igualdad } \\
\text { de género y al empoderamiento de las mujeres. }\end{array}$ \\
\hline \multirow{7}{*}{$\begin{array}{l}\text { Conflicto armado } \\
\text { y violencia contra } \\
\text { la mujer }\end{array}$} & 2000 & Resolución 1325 del Consejo de Seguridad. \\
\hline & $2000-2004$ & $\begin{array}{l}\text { Resolución de la Asamblea General sobre la eliminación de toda } \\
\text { forma de violencia contra las mujeres. }\end{array}$ \\
\hline & $2000-2004$ & $\begin{array}{l}\text { Resolución de la Asamblea General: Hacia la eliminación de los } \\
\text { delitos de honor cometidos contra las mujeres. }\end{array}$ \\
\hline & $2006-2010$ & $\begin{array}{l}\text { Resolución de la Asamblea General sobre la intensificación de } \\
\text { los esfuerzos para eliminar todas las formas de violencia contra } \\
\text { las mujeres. }\end{array}$ \\
\hline & 2007 & $\begin{array}{l}\text { Resolución de la Asamblea General sobre protección y asistencia } \\
\text { a los desplazados internos. }\end{array}$ \\
\hline & 2009 & Resolución 1889 del Consejo de Seguridad. \\
\hline & 2010 & $\begin{array}{l}\text { Resolución del Consejo de Derechos Humanos sobre acelerar los } \\
\text { esfuerzos para eliminar todas las formas de violencia contra las } \\
\text { mujeres: garantizar la debida diligencia en la prevención. }\end{array}$ \\
\hline
\end{tabular}

Fuente: Adaptación a partir del marco jurídico para la mujer de organizaciones internacionales

En definitiva, sobresalen ampliamente los documentos a favor de la mujer, en cuanto al conflicto armado y violencia, salud sexual y reproductiva, explotación sexual, derecho laboral y humano. Ellos contienen, el mayor número de refrendación legal, que salvaguardan la integridad de la mujer en los diferentes escenarios y permiten mayor ascenso social. 


\section{VISIBILIDAD ACADÉMICA EN ESTUDIOS DE GÉNERO}

De acuerdo a los antecedentes contextuales, la mujer se pronunció en relación a la visibilidad de lo femenino en las distintas aristas existenciales; de ahí se fueron concretando a estudios con esa incorporación. Unido al movimiento feminista y luego la teoría feminista, el reconocimiento de la mujer a través de organismos internacionales como la ONU que inicia desde 1975, y luego a mediados de los noventa, el desarrollo de la cuarta conferencia de la Mujer desarrollada en Beijing, se logra en acuerdo con los gobiernos la transversalización del género como construcción social; es allí, que los estudios con integración de la mujer, se articulan con todos los procesos históricos.

Se articulan aquí los centros de investigaciones en estudios de género alrededor del mundo, como también observatorios, agencias internacionales comprometidas a través de investigaciones regionales, sumado a las tendencias internacionales (latinoamericanas e iberoamericanas) y nacionales (Colombia), de investigaciones que representan la educación y la ciudadanía, educación intercultural y género, y finalmente, representaciones femeninas en los gobiernos escolares.

\section{Exploración institucional de los estudios de género}

En la actualidad hay una tendencia investigativa por los estudios que integran lo femenino. Aquí se compilan abordajes, por el interés investigativo, desde plano internacional, latinoamericano, iberoamericano y colombiano. Sobresalen países como Estados Unidos, donde se concentra el $81 \%$ de las investigaciones del total de países -según una pesquisa informática 2013desde diferentes perspectivas, con abordajes desde la historia, la filosofía, la justicia y la educación. En América Latina, cabe 
destacar el papel de la CEPAL en estos estudios, como también la creciente consolidación de los observatorios de temáticas inherentes al género.

\section{Internacional}

Consecuente con lo descrito anteriormente, además de búsquedas activas tanto en centros de Instituciones de educación superior y desarrollo de investigaciones en el tema como en organismos internacionales en la competencia del tema (ONU, CEPAL), ONG que trabajan en esa línea, encontramos lo siguiente:

En una primera exploración, se encontró que existen 935 centros en el nivel pregrado y posgrado, alrededor del mundo (Korenman, 2013) de los cuales el $82 \%$ está concentrada en el continente americano; en ese orden solamente en Estados Unidos le pertenece un $74 \%$, Canadá un 6,1 \% y América Latina un 2,1 \%. El 19,3\% restante está distribuido en Europa en un 9,6\%, Asia $6,3 \%$, Oceanía 1,3 \% y África un 2,1\%. A continuación se hace una síntesis (ver Tabla 3).

Clausurando este segmento, hay que reconocer el desafío que existe en América Latina, que integra solo un 2,1\% de los centros de investigación en relación a los estudios de género, lo que refuerza poder afirmar que es indispensable continuar con estas líneas de estudio, que permitirán iluminar el camino para transformar socialmente, sobre todo en los entramados institucionales y la manera de cómo pueden ir diluyendo las diferenciaciones que han segmentado, la integración sociocultural de la mujer en las diferentes instancias, tanto del nivel público, como el privado. 
Historicidad del reconocimiento femenino en contraste con la participación escolar: una mirada intercultural, departamento del Atlántico-Caribe colombiano

Tabla 3

Síntesis de instituciones de educación superior, con estudios de género en el mundo

\begin{tabular}{|c|c|c|}
\hline Continente & País & $\begin{array}{c}\text { Centros de estudios } \\
\text { superiores e investigaciones }\end{array}$ \\
\hline América del Norte & Estados Unidos & $692(91 \%)(74 \%)$ \\
\hline \multirow{8}{*}{ América Latina } & Argentina & 2 \\
\hline & Chile & 3 \\
\hline & Colombia & 4 \\
\hline & Costa Rica & 2 \\
\hline & República Dominicana & 1 \\
\hline & México & 2 \\
\hline & Perú & 1 \\
\hline & Venezuela & 1 \\
\hline \multirow[t]{2}{*}{ Total } & & $16(2,1 \%)$ \\
\hline & Canadá & $46(6,1 \%)$ \\
\hline Total & & $754(81 \%)$ \\
\hline \multirow{9}{*}{ Europa } & Francia & 6 \\
\hline & España & 5 \\
\hline & Reino Unido & 32 \\
\hline & Suecia & 10 \\
\hline & Suiza & 7 \\
\hline & Noruega & 4 \\
\hline & Alemania & 12 \\
\hline & Finlandia & 9 \\
\hline & Grecia & 5 \\
\hline Total & & $90(9,6 \%)$ \\
\hline \multirow{5}{*}{ Asia } & China & 2 \\
\hline & India & 5 \\
\hline & Israel & 5 \\
\hline & Rusia & 46 \\
\hline & Palestina & 1 \\
\hline Total & & $59(6,3 \%)$ \\
\hline \multirow[t]{2}{*}{ Oceanía } & Nueva Zelanda & 6 \\
\hline & Australia & 6 \\
\hline Total & & $12(1,3 \%)$ \\
\hline \multirow{3}{*}{ África } & Sudán & 12 \\
\hline & Sudáfrica & 6 \\
\hline & Egipto & 2 \\
\hline Total & & $20(2,13 \%)$ \\
\hline Gran Total & & $935(100 \%)$ \\
\hline
\end{tabular}

Fuente: Adaptación, a partir del Website Joan Korenman 2014 y otras búsquedas individuales. Diciembre, 2014 


\section{Iberoamérica}

De acuerdo a la anterior búsqueda, se tomó una muestra, donde se confirmaron los website ${ }^{3}$ en un $30 \%$ de las Universidades vigentes. De la totalidad de centros que accedieron a 935, distribuidos en los cinco continentes, se tomó una muestra representativa del 2,3\%, correspondiente a un país europeo (España) y 8 países latinoamericanos (Argentina, Brasil, Chile, Colombia, Costa Rica, Mexico, Perú y Venezuela,), reconfirmando el acceso otorgado por la pagina web referenciada anteriormente.

Se encontró, un total de 21 universidades, de las cuales un $30 \%$ corresponden a España y $70 \%$ a América Latina; de ellos son de carácter público en su mayoría (86\%), el resto son privadas.

Finalmente, dentro de las líneas de investigación más asistidas en lo relacionado al género, está la preferencia por el abordaje de los temas de filosofía (30\%) e historia (18\%) los temas como educación y participación social solamente $(7 \%$ para cada uno).

\section{CEPAL}

Para el caso de América Latina, desde la década de los setenta se delegó en la CEPAL, a través de la división de asuntos de género, lo relacionado a las movilidades con 11 conferencias realizadas desde 1977 (Ver Tabla 4), de lo que han derivado 125 estudios de investigación, llevados a cabo en diferentes países a través de las series Mujer y Desarrollo; también se han publicado 27 libros. Para ambos casos la fecha de inicio es la década de los noventa; y por último en la creación del observatorio de

3 La autora del Website es la docente de la Universidad de Maryland, Estados Unidos, Joan Korenman; profesora emérita, y fundadora del Centro de Estudios para la Mujer y la Tecnología de la Información en la Universidad de Maryland, Baltimore County (UMBC); desde diciembre 1999. 
igualdad de género de América Latina y el Caribe en el año 2007 (ver Tabla 5).

A continuación se precisan en detalle, las once conferencias; entre estas y el observatorio, mayormente se enfocan en el tema de la igualdad; ambas excluyen de manera general el tema educativo específicamente, aunque de manera transversal lo integran (ver Tabla 4).

Tabla 4

Síntesis de conferencias regionales A.L CEPAL. 1977-2010

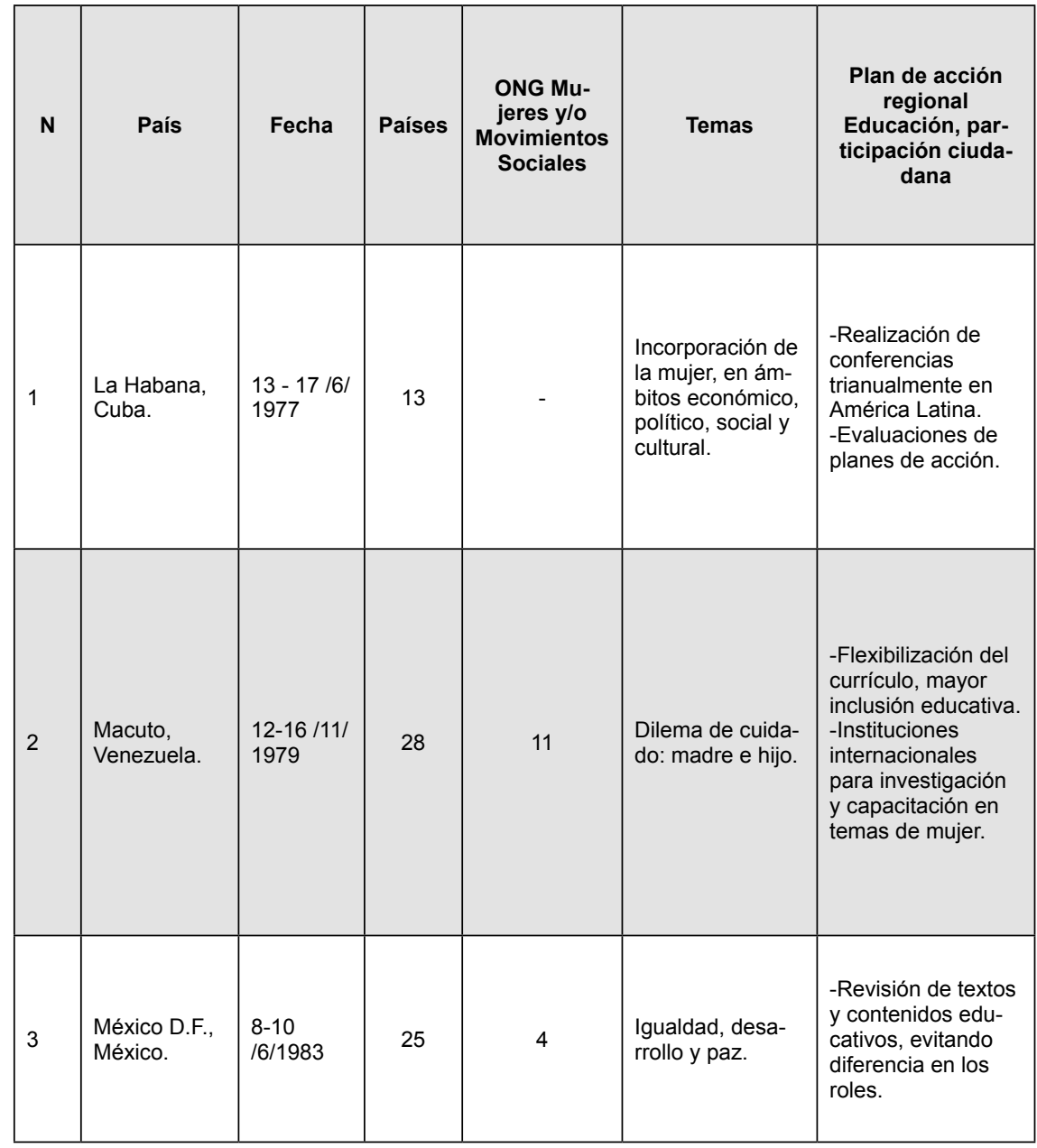

Tabla 4 (Continúa) 
Tabla 4 (Viene)

\begin{tabular}{|c|c|c|c|c|c|c|}
\hline 4 & $\begin{array}{l}\text { Ciudad de } \\
\text { Guatemala, } \\
\text { Guatemala. }\end{array}$ & $\begin{array}{l}27-30 / 9 / \\
1988\end{array}$ & 30 & ND & $\begin{array}{l}\text { Maltrato y violen- } \\
\text { cia a la mujer. }\end{array}$ & $\begin{array}{l}\text {-Fomentar el acce- } \\
\text { so a la educación } \\
\text { en todos los niveles } \\
\text { (indígenas, campe- } \\
\text { sinas). } \\
\text {-Motivar la partici- } \\
\text { pación política de } \\
\text { la mujer, desde los } \\
\text { niveles de ONG y } \\
\text { movimientos femi- } \\
\text { nistas. }\end{array}$ \\
\hline 5 & $\begin{array}{l}\text { Curazao, } \\
\text { Antillas Neer- } \\
\text { landesas. }\end{array}$ & $\begin{array}{l}16-19 \\
/ 9 / 1991\end{array}$ & 37 & 3 & $\begin{array}{l}\text { Transformación } \\
\text { productiva con } \\
\text { equidad y la } \\
\text { integración de la } \\
\text { mujer al desa- } \\
\text { rrollo. }\end{array}$ & $\begin{array}{l}\text {-Eliminar las ba- } \\
\text { rreras que impiden } \\
\text { a la mujer, la } \\
\text { participación demo- } \\
\text { crática. }\end{array}$ \\
\hline 6 & $\begin{array}{l}\text { Mar del } \\
\text { Plata, Argen- } \\
\text { tina. }\end{array}$ & $\begin{array}{l}25-29 \\
19 / 1994\end{array}$ & 56 & 23 & $\begin{array}{l}\text { Igualdad de } \\
\text { oportunidades: } \\
\text { tierra, capacita- } \\
\text { ción. Mujeres mi- } \\
\text { grantes, madres } \\
\text { adolescentes y } \\
\text { campesinas. }\end{array}$ & $\begin{array}{l}\text {-Participación en } \\
\text { Beijing. } \\
\text { - Adquisición de } \\
\text { poder en cargos de } \\
\text { elección popular. }\end{array}$ \\
\hline 7 & $\begin{array}{l}\text { Santiago de } \\
\text { Chile, Chile. }\end{array}$ & $\begin{array}{l}19-21 \\
/ 11 / 1997\end{array}$ & 28 & ND & $\begin{array}{l}\text { Acceso al poder } \\
\text { y participación } \\
\text { en la toma de } \\
\text { decisiones. }\end{array}$ & $\begin{array}{l}\text {-Desarrollo soste- } \\
\text { nible, pobreza y } \\
\text { género. }\end{array}$ \\
\hline 8 & Lima, Perú. & $\begin{array}{l}8-10 / 2 / \\
2000\end{array}$ & 49 & $\begin{array}{l}\quad 31 \\
\text { Aso. Diversi- } \\
\text { dad sexual. }\end{array}$ & $\begin{array}{l}\text { Equidad de gé- } \\
\text { nero y derechos } \\
\text { humanos. }\end{array}$ & $\begin{array}{l}\text {-Fortalecimiento de } \\
\text { la educación, para } \\
\text { el desarrollo. } \\
\text { - Apoyar el trabajo } \\
\text { en red. }\end{array}$ \\
\hline 9 & $\begin{array}{l}\text { México D.F., } \\
\text { México. }\end{array}$ & $\begin{array}{l}10-12 \\
/ 6 / 2004\end{array}$ & ND & ND & $\begin{array}{l}\text { Igualdad de } \\
\text { género, empo- } \\
\text { deramiento y } \\
\text { política. }\end{array}$ & $\begin{array}{l}\text {-Investigación en } \\
\text { temas de género. } \\
\text {-Reformas educa- } \\
\text { tivas. }\end{array}$ \\
\hline 10 & $\begin{array}{l}\text { Quito, Ecua- } \\
\text { dor. }\end{array}$ & $\begin{array}{l}6-9 / 8 / \\
2007\end{array}$ & 36 & $\begin{array}{l}\quad 23 \\
\text { Carta de mu- } \\
\text { jeres indíge- } \\
\text { nas América } \\
\text { Latina. }\end{array}$ & $\begin{array}{l}\text { Aporte de la mu- } \\
\text { jer a la igualdad }\end{array}$ & $\begin{array}{l}\text {-Ampliar la demo- } \\
\text { cracia participativa. } \\
\text {-Fomento de la } \\
\text { participación de la } \\
\text { mujer a nivel inter- } \\
\text { nacional. }\end{array}$ \\
\hline 11 & $\begin{array}{l}\text { Brasilia, } \\
\text { Brasil. }\end{array}$ & $\begin{array}{l}13-16 \\
/ 7 / 2010\end{array}$ & 32 & $\begin{array}{l}\quad 43 \\
\text { Carta de mu- } \\
\text { jeres feminis- } \\
\text { tas América } \\
\text { Latina }\end{array}$ & $\begin{array}{l}\text { ¿Qué estado, } \\
\text { para qué igual- } \\
\text { dad? }\end{array}$ & $\begin{array}{l}\text {-Capacitación en } \\
\text { TIC. } \\
\text {-Capacitación en } \\
\text { género. } \\
\text {-Ciudadanía. }\end{array}$ \\
\hline
\end{tabular}

Fuente: Adaptación, a partir de las 11 conferencias realizadas para la integración de la mujer en América Latina: 1977-2010. (CEPAL) 
Según la Tabla 4, en tres de las once conferencias se aborda el tema de género de manera central, correspondiendo a un $25 \%$ tema que efectivamente viene apareciendo desde finales de los noventa, coincidiendo con la plataforma de acción de Beijing. Para el caso del observatorio, que tiene tres dimensiones: autonomía física, autonomía en la toma de decisiones y autonomía económica, la segunda es significativa a esta investigación, debido a que se relaciona con las cifras de la participación real de las mujeres en los cargos públicos y de elección popular.

Ahora bien, en cuanto a la producción intelectual en temas de género, desde la CEPAL, están por un lado: los libros de la división, y por otro, la serie de mujer y desarrollo (ver Tabla 5 y Gráfico 1). De los primeros, con la existencia de 27 volúmenes, sólo un $5 \%$ están relacionados a la participación social; en su mayoría estas publicaciones se dedican en un $70 \%$ a temas de igualdad y equidad, un $20 \%$ al tema de discriminación y un $5 \%$ a informes varios.

En cuanto a las segundas, que a corte de julio del año 2013 existen registradas 125 investigaciones específicamente están enfocadas mayormente en un $28 \%$ a condiciones laborales, un $15 \%$ equidad, $13 \%$ género y un $13 \%$ temas variados; continuando en la escala porcentual en un $9 \%$ violencia, $6 \%$ política y participación ciudadana y $5 \%$ vulnerabilidad. Y en mínimo porcentaje pero no así en la magnitud de las complejidades abordadas sobre el tema, aspectos relacionados con la salud, desarrollo, cultura, población y educación en un 3\% e igual forma en un $2 \%$ en TIC y Mundo privado de la mujer (CEPAL, 2013) (ver Gráfico 1). 
ESTUDIOS DOCTORALES FEMENINOS:

Aportes desde las Ciencias Sociales y Humanas

Tabla 5

Síntesis de publicaciones de la CEPAL-división género

(Educación y participación). 1977-2013

\begin{tabular}{|c|c|c|c|c|c|c|c|}
\hline \multirow{3}{*}{$\mathbf{N}$} & \multirow{3}{*}{ Publicaciones } & \multirow{3}{*}{ Periodo } & \multirow{3}{*}{ Cantidad } & \multicolumn{4}{|c|}{ Tema } \\
\hline & & & & \multicolumn{2}{|c|}{ Educación } & \multicolumn{2}{|c|}{ Participación } \\
\hline & & & & Cant & $\%$ & Cant & $\%$ \\
\hline 1 & $\begin{array}{l}\text { Conferencias regio- } \\
\text { nales en América } \\
\text { Latina. }\end{array}$ & $1977-2013$ & $\begin{array}{l}11 \text { Conferen- } \\
\text { cias }\end{array}$ & - & - & 3 & $25 \%$ \\
\hline 2 & $\begin{array}{l}\text { Investigaciones: } \\
\text { series mujer y desa- } \\
\text { rrollo. }\end{array}$ & $1989-2013$ & $\begin{array}{l}125 \text { publica- } \\
\text { ciones }\end{array}$ & 3 & $2,4 \%$ & 8 & $6,4 \%$ \\
\hline 3 & Libros de la división. & 1999-2013 & 27 libros & - & - & 5 & $18,5 \%$ \\
\hline 4 & $\begin{array}{l}\text { Observatorio de igual- } \\
\text { dad género de América } \\
\text { Latina y el Caribe. }\end{array}$ & 2007 & $\begin{array}{l}1 \text { Observa- } \\
\text { torio } \\
3 \text { temas }\end{array}$ & - & - & 1 & $33 \%$ \\
\hline & Total & & 167 & 3 & $1,7 \%$ & 17 & $10,2 \%$ \\
\hline
\end{tabular}

Fuente: Análisis de las publicaciones de la CEPAL, división género, en educación y participación 1977-2013

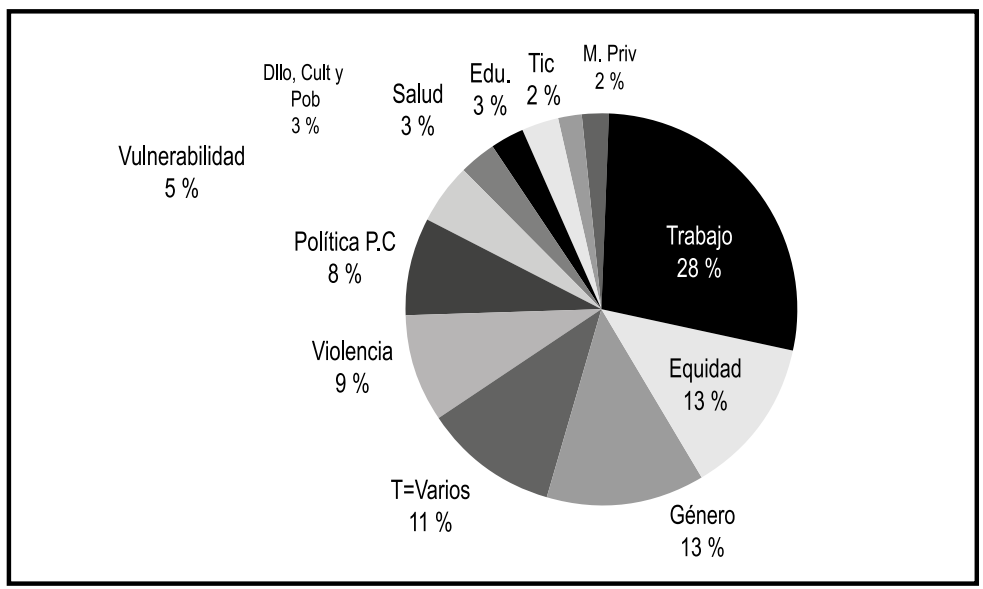

Gráfico 1

Resumen porcentual de 125 documentos de la CEPAL, Género 1989-2013

Fuente: Adaptación propia a partir de análisis de 125 documentos de la CEPAL

El aporte por parte de la división de asuntos de género de la CEPAL en América Latina al tema de género y específicamente a educación y participación social es: en el primer ítem, son tres estudios de la serie Mujer y desarrollo, correspondiente al 2,4 \% del total 
de las investigaciones y para el segundo, tres conferencias regionales, ocho investigaciones; además, cinco libros y una dimensión del observatorio de igualdad de género, que porcentualmente está delimitado en $25 \%, 6,4 \%, 18 \%$ y $33 \%$, respectivamente. En lo anterior, se constata que se requiere abordar investigaciones con enclave de género desde el área que estamos nos estamos aproximando aquí, ya que resulta vital que el sector de la educación trabaje desde la primera infancia en el empoderamiento de las niñas, con el fin de potenciar su rol como líderes políticas del futuro; ellas crearán condiciones de desarrollo para nuestros países, tal y como lo han hecho las mujeres (CEPAL, 2011).

\section{Observatorios de género}

Mediante una exploración a través de la web, dentro del contexto Iberoamericano se localizaron once sitios que contienen observatorios de género; entre ellos tenemos a España, en Madrid; en América Latina: Argentina, México, Colombia, Venezuela, Ecuador y Chile; lo anterior contrastado con el observatorio de género de la CEPAL, que desde 2007 procesa los datos en relación al género. Sus inicios datan desde mediados de la década del noventa, lo cual coincide con la cuarta conferencia de la mujer en Beijing, donde se logra la transversalización del género a nivel mundial (ver Tabla 6).

Tabla 6

Síntesis de observatorios de género en Iberoamérica

\begin{tabular}{|c|l|l|l|}
\hline $\mathbf{N}$ & \multicolumn{1}{|c|}{ Observatorio } & \multicolumn{1}{c|}{ País } & \multicolumn{1}{c|}{ Líneas de Acción } \\
\hline 1 & $\begin{array}{l}\text { Observatorio de Gé- } \\
\text { nero y Pobreza en } \\
\text { Argentina. }\end{array}$ & Argentina, 1995. & $\begin{array}{l}\text { Televisión, radio, prensa, Internet y } \\
\text { vía publica. }\end{array}$ \\
\hline 2 & $\begin{array}{l}\text { El Observatorio Ciu- } \\
\text { dadano por la Equidad } \\
\text { de Género en los } \\
\text { Medios de Comuni- } \\
\text { cación. }\end{array}$ & $\begin{array}{l}\text { México, 1999, por iniciativa de } \\
\text { un grupo de comunicadoras, } \\
\text { profesionales de la radio. }\end{array}$ & Derecho Laboral, violencia de género. \\
\hline \multicolumn{2}{|l}{}
\end{tabular}


ESTUDIOS DOCTORALES FEMENINOS:

Aportes desde las Ciencias Sociales y Humanas

Tabla 6 (Viene)

\begin{tabular}{|c|c|c|c|}
\hline & & & Tabla 6 (Viene) \\
\hline 3 & $\begin{array}{l}\text { Women's Link World- } \\
\text { wide. }\end{array}$ & $\begin{array}{l}\text { Link fue fundada en } 2001 \text { y } \\
\text { posee estatus } 501(\mathrm{c})(3) \text { en los } \\
\text { términos de las leyes de los } \\
\text { Estados Unidos, estatus de } \\
\text { fundación en España y estatus } \\
\text { de organización no gubermental } \\
\text { en Colombia. Tenemos oficinas } \\
\text { regionales en Europa (Madrid, } \\
\text { España) y Latinoamérica (Bo- } \\
\text { gotá, Colombia). }\end{array}$ & $\begin{array}{l}\text { Derechos sexuales y reproductivos, } \\
\text { violencia de género, discriminación } \\
\text { por género. }\end{array}$ \\
\hline 4 & $\begin{array}{l}\text { El Observatorio del } \\
\text { derecho de las muje- } \\
\text { res y las niñas. }\end{array}$ & Ecuador, 2003 & Violencia de género. \\
\hline 5 & $\begin{array}{l}\text { Observatorio asuntos } \\
\text { de género. }\end{array}$ & Colombia, 2004 & $\begin{array}{l}\text { Prevención de violencia contra las } \\
\text { mujeres. } \\
\text { Participación de la mujer en el merca- } \\
\text { do laboral. } \\
\text { Participación política de las mujeres. } \\
\text { Mecanismos de seguimiento e inves- } \\
\text { tigación. } \\
\text { Salud sexual y reproductiva. }\end{array}$ \\
\hline 6 & $\begin{array}{l}\text { Observatorio de la } \\
\text { violencia de género. }\end{array}$ & $\begin{array}{l}\text { Fundación Mujeres, Madrid, } \\
2006\end{array}$ & $\begin{array}{l}\text { Violencia de género. } \\
\text { Feminicidios. }\end{array}$ \\
\hline 7 & $\begin{array}{l}\text { El Observatorio Vene- } \\
\text { zolano de los Dere- } \\
\text { chos Humanos de las } \\
\text { Mujeres. }\end{array}$ & Venezuela, 2006 & Derechos humanos de las mujeres. \\
\hline 8 & $\begin{array}{l}\text { Observatorio de } \\
\text { igualdad de género } \\
\text { de América Latina y el } \\
\text { Caribe. }\end{array}$ & $\begin{array}{l}\text { La División de Asuntos de Gé- } \\
\text { nero de la Comisión Económica } \\
\text { para América Latina y el Caribe } \\
\text { (CEPAL), } 2007\end{array}$ & $\begin{array}{l}\text { Autonomía física. } \\
\text { Autonomía en la toma de decisiones. } \\
\text { Autonomía económica. }\end{array}$ \\
\hline 9 & $\begin{array}{l}\text { Observatorio de géne- } \\
\text { ro y equidad. }\end{array}$ & Chile, 2010 & Autonomía política de la mujer. \\
\hline 10 & $\begin{array}{l}\text { Observatorio de géne- } \\
\text { ro y pobreza. }\end{array}$ & $\begin{array}{l}\text { México. El Observatorio de } \\
\text { Género y Pobreza (OGP) es un } \\
\text { proyecto conjunto de El Colegio } \\
\text { de México (COLMEX), el Fondo } \\
\text { de Desarrollo de las Naciones } \\
\text { Unidas para la Mujer (UNIFEM), } \\
\text { el Instituto Nacional de Desa- } \\
\text { rrollo Social (INDESOL), y el } \\
\text { Instituto Nacional de las Muje- } \\
\text { res (INMUJERES). }\end{array}$ & $\begin{array}{l}\text { Las dimensiones objetivas, es decir, } \\
\text { en factores sociodemográficos como } \\
\text { edad y sexo, y otros factores contex- } \\
\text { tuales. } \\
\text { Las dimensiones subjetivas. }\end{array}$ \\
\hline 11 & $\begin{array}{l}\text { El Observatorio de } \\
\text { Género. }\end{array}$ & $\begin{array}{l}\text { Derecho Constitucional, Univer- } \\
\text { sidades Carlos III de Madrid y } \\
\text { Universidad Nacional de Educa- } \\
\text { ción a Distancia (UNED.) }\end{array}$ & $\begin{array}{l}\text { Ciudadanía y derechos políticos, } \\
\text { Violencia de género, } \\
\text { Educación y estereotipos sexuales, } \\
\text { Economía y empleo. } \\
\text { Educación sexual y reproductiva, }\end{array}$ \\
\hline
\end{tabular}

Fuente: Elaboración propia, a partir de páginas web de cada uno de los observatorios 
Según se constata en la Tabla 6 , en cuanto a las temáticas consideradas como referente en los observatorios consultados en el país europeo, los dos observatorios consultados, las líneas de acción coinciden con las temáticas relacionadas a la violencia de género, salud sexual y reproductiva, y discriminación de género.

En ese sentido, en América Latina, por ejemplo, todos coinciden con la violencia de género, exceptuando a Argentina, que se enfoca más por la representación femenina en medios comunicacionales como la televisión, prensa, Internet y vía pública. El tema de análisis de participación en política de la mujer lo encontramos específicamente en uno de los dos observatorios de España y en el correspondiente a países como Colombia y Chile. Cabe anotar también la importancia que tiene el observatorio de la CEPAL, el cual prioriza además de la autonomía física, la toma de decisiones y económica de la mujer, y sistematiza los datos a nivel de América Latina, favoreciendo el seguimiento en el cumplimiento de la ley de cuotas, por ejemplo, y la integración de la mujer en los cargos dentro de la función pública (ver Tabla $6)$.

Al analizar los párrafos anteriores, el abordaje del género tiene múltiples variables; lo preponderante es que en el caso de la mujer, los indicadores demuestran qué tanto se puede seguir trabajando por ello y el compromiso, no solo de los gobiernos, sino también de la ciudadanía, la comunidad académica, las nuevas masculinidades, para que unidos se puedan abrir espacios participativos que continúen visibilizando esas situaciones que desvirtúan el mundo de vida de mujeres particularmente, siendo aquellas que están en vulnerabilidad las que se encuentran en mayor riesgo de no poder potenciar y desarrollarse en su contexto, desde la política social y la inclusión educativa. 


\section{Líneas de investigación en género: instituciones de educación superior}

Avizorando, tanto a nivel iberoamericano, latinoamericano y colombiano, en relación a las tendencias de investigación en línea de género, hay una productividad creciente en aspectos específicos como el feminismo, historia, violencia, política pública e igualdad de oportunidades; sin embargo decrecen los estudios que integren la educación y la participación ciudadana en el espacio escolar lo que permite constatar que es interesante la delimitación de esta tesis, además dentro de la perspectiva intercultural, que facilita mayores abstracciones ahí en el espacio escolar. En lo que sigue, se confirma lo anteriormente descrito.

Internacional

Para referirnos a los estudios e investigaciones de este tipo, es significativo lo que define su interés como los aspectos contextuales. Por ejemplo, la convención de los derechos del niño, por la UNICEF en el año 1989, como la transversalización de género logrado en la plataforma de la IV Conferencia mundial de la mujer en Beijíng para mediados de la década de los noventa, coincide con el inicio de los estudios de la mujer dentro de la contemporaneidad. Es así que tomamos una muestra en siete universidades de España y América Latina para identificar específicamente sus líneas de investigación, que en la mayoría del inicio de estudios proceden a partir de finales de los años 80 , principios de los 90 .

Ahora iniciamos un análisis de los centros de investigación de las universidades que integraron la búsqueda eligiendo una muestra representativa desde España, a través de la Universidad Complutense de Madrid ${ }^{4}$, Universidad de Salamanca ${ }^{5}$ y 
Universidad de Barcelona ${ }^{6}$; lo cual, a diferencia de los grupos o centros de investigación de Universidades de América Latina, sus integrantes son líderes en el debate de la teoría feminista como en el caso de Celia Amorós, en la Universidad Complutense, quien es autora de una variedad de obras que aportan desde la teoría feminista, a su vez integrando su área de filosofía, articulada con el feminismo y el multiculturalismo.

En cuanto al primer centro de educación superior, se han especializado desde lo femenino en teoría feminista, historia, literatura, arte; en relación al segundo, representaciones, igualdad y discapacidad; y la tercera, especificamente en filosofía e identidades. Lo que nos indica que no han considerado, la participacion femenina en los espacios democráticos en la escuela.

En lo referente a países como México, Costa Rica, Argentina y Chile, indagamos por ejemplo, que en las Universidades Autónoma, Costa Rica, Flacso y Chile repectivamente, las líneas de estudio para ese mismo orden se proyectan hacia el feminismo, arte y ciudadanía, violencia doméstica, etnia, participación política; política pública, violencia e igualdad de oportunidades, género en la politica pública, especificamente el área de salud, etnicidad.

En definitiva, con base en la información detallada anteriormente, se puede afirmar que en el tema de género en lo específico de mujer, se han inclinado los estudios hacia la teoría feminista, la violencia, filosofía, igualdad; sin embargo los pocos centros de investigación que integran la educación y la participación social, no la contextualizan dentro del espacio social de la escuela, encontrando así mayor relevancia este estudio que

6 El Seminario de Estudios sobre la Producción Filosófica de las Mujeres, "Filosofía y Género". 
busca identificar los factores que favorecen/desfavorecen la movilidad de las/los estudiantes en cuanto a la participación social, dentro de los espacios donde legalmente pueden hacerlo, al interior de las instituciones.

\section{En Colombia}

En tanto la revision realizada a las universidades colombianas a través de instituciones de educación superior, como son, la Nacional, Valle y Atlántico, encontramos que en la primera, ubicada en Bogotá, existe una Escuela de estudios de género, con extensiones de formación avanzada en cuanto a especialización y maestría, y en general su línea de investigación se orienta hacia el pensamiento feminista y de la perspectiva de género en los estudios sociales en Colombia. La segunda, con sede en Cali, tiene establecido un Centro de estudios de género Mujer y sociedad en el cual las líneas de estudio se dirigen hacia la literatura, etnicidad, familia y política. Y la tercera, ubicada en el contexto de este estudio, en Barranquilla, efectivamente se evidenció que el grupo de investigación está insertado en el Centro de documentación Meira Delmar, en el cual se han especializado en las temáticas como análisis de lo femenino en relación a la política pública, cultura, educación, y participación social.

Finalmente, considerando lo anterior, vale la pena aportar que los estudios en este país a través de las líneas descritas anteriormente, hay una relación entre lo femenino y la sociedad, encontrando parte de la realidad en los estudios étnicos y sociales, y solo en una universidad existe una aproximación al tema que delimitamos aquí, como es la educación y la participación social, pero no hay estudios delimitados en el ámbito escolar sino a nivel macro. 


\section{Estudios empíricos en género: primaria y media,}

\section{por agencias internacionales}

Los organismos internacionales como la PREAL, UNICEF, OEA, aunado con estudiosos del tema e instituciones de los gobiernos nacionales en el contexto de América Latina y Colombia han considerado propicio el estudio del liderazgo estudiantil, en la enseñanza primaria y media, que encumbre los límites existentes actuales y permita mayor apertura del tema, como aporte a políticas públicas, inclusivas y con tendencia paritaria. En ese sentido, lo confirman las síntesis que a continuación se presentan.

\section{Internacional}

La organización de las escuelas y las estructuras que en ellas se ocupan de tomar decisiones, por lo general son jerárquicas, formales y poco democráticas. En numerosos países, la mayor parte del poder se concentra en las manos del director, que a su vez es responsable del funcionamiento de la escuela ante un ente administrativo oficial. Todas las decisiones relacionadas con la escuela se toman haciendo caso omiso de los niños de la manera más absoluta. Sin embargo, la implementación de la Convención implica que los gobiernos deberían crear oportunidades para que los niños puedan intervenir en la toma de decisiones a todos los niveles del funcionamiento de la escuela $y$, para que esto suceda, es necesario que existan estructuras democráticas tales como horas de debate, consejos escolares y mecanismos de representación en los organismos administrativos, de manera que se asegure la participación activa de los niños (UNICEF, 1998, p.62).

Coincide con lo anterior, un análisis que hizo la OEA (2010), lo cual demuestra que en la escuela tanto niñas como niños, están inmersos en un ámbito donde en ocasiones encuentran los mayores obstáculos en cuanto a la participación infantil debido a 
la distribución jerárquica y vertical del poder. El contacto con los funcionarios, docentes y autoridades lo enfrentará a la experiencia de relacionarse con adultos que ejercen un poder institucional, o sea aquel que no deriva de la persona sino del lugar que ocupa (OEA, 2010, p.37).

La participación es un derecho de todos los seres humanos incluyendo los niños y niñas, sin discriminación de ningún tipo. En julio de 2009, el Comité de los Derechos del Niño, en su Observación General N $N^{0} 12$, realizó una interpretación amplia y algunas expresiones contenidas en la Convención y que suelen ser interpretadas como restricciones al derecho a la participación. Tal es el caso de niños y niñas "capaces de formarse un juicio propio", o "los asuntos que afectan al niño" donde se incluyen los temas sociales y de su comunidad (OEA, 2010, p.33).

Por tanto, la participación debe darse en todos los ámbitos y escenarios donde se desarrollan y ponen en práctica estas decisiones. En este sentido, toman importancia tanto los referidos a la vida cotidiana, como familia, escuela, espacios comunitarios, y los de instituciones a las cuales los niños concurren en situaciones críticas (salud, justicia), como la propia esfera pública donde se toman decisiones, ya sea a nivel local, provincial o nacional.

A nivel general, en la participación femenina, tanto en la vida política y pública, se encontró un estudio que por un lapso de tres años (2009-2011) aplicado a dieciséis países de América Latina, Central, Andina y El Caribe ${ }^{7}$, se consultó a un conjunto de líderes políticos, religiosos, sociales, culturales como también

7 La paridad política en América Latina y el Caribe. Percepciones y opiniones de los líderes de la región. CEPAL 2011. 
a comunicadores y empresarios, tanto hombres como mujeres sobre sus percepciones en relación a las desigualdades existentes en el ámbito político y la inclusión de género, así como sus evaluaciones sobre las condiciones para el avance de la paridad política de género y las posibles barreras para este proceso (CEPAL, 2011).

Dentro de los resultados más relevantes, se encontraron que en un $80 \%$, los entrevistados están de acuerdo en el incremento de la mujer en la participación política; aunque los hombres se demuestran más favorables que las mujeres en un $90 \%$. Se podría relacionar lo anterior con la imagen positiva que representa para los consultados, el hecho de que existan mujeres presidentes en la región, debido a que se generan políticas públicas y existe inclusión de género en cargos públicos. Aunque las expectativas en relación a la participación a corto plazo de la mujer la miran sin ninguna variación, manteniéndose en $48 \%$ de aceptación, en el largo plazo, lo asimilan con más optimismo en un $86 \%$. Finalmente, en un $80 \%$ la paridad política representa aceptación como una manera de generar oportunidades de participación en las mujeres.

En ese sentido, en América Latina a diferencia de Europa y América del Norte, donde se trabaja más la representación en cuanto a la participación ciudadana dentro de la escuela, a continuación presentamos estudios de organismos internacionales que dan cuenta del interés por la temática en referencia:

- Un estudio de la PREAL (2006), desarrollado en siete países entre Centro y Latinoamérica (Bolivia, Brasil, Colombia, El Salvador, Guatemala, Honduras, Nicaragua), centrado en la participación de la comunidad educativa, específicamente los padres, demostró que en los países en mención 
la norma ha definido la creación de organismos colegiados -consejos escolares o directivos, juntas escolares-en los que participan en ocasiones solamente los padres y miembros de la comunidad local, y otras veces estos mismos en conjunto con otros actores como son el director, docentes, estudiantes y miembros de la comunidad local. Se puede asociar entonces la creación de estas instancias a un esquema de participación inducida por el Estado. Adicionalmente, funcionan en algunos casos asambleas y asociaciones como organizaciones civiles con personería jurídica y sin ánimo de lucro, primordialmente para recibir recursos que se giran directamente a la escuela (PREAL, 2006, p.14)

- Otro estudio realizado en Chile, por Contreras y Pérez (2011), donde los resultados evidencian que en las zonas del país donde se ubicó el estudio, están lejos de producir una cultura de derechos; no obstante, niños y niñas participan para poder posicionarse como protagonistas de sus propias vidas y sociedad. En este sentido, es necesario resaltar que de los mismos niños y niñas nacen propuestas de trabajo y desafíos a cumplir en torno a la participación (Contreras y Pérez, 2011, p.811).

- En Honduras, Sánchez (2005), en un estudio de la organización y funcionamiento de los gobiernos escolares y estudiantiles en municipios de cinco departamentos de ese país se obtuvo, dentro de los resultados más relevantes, según las entrevistas hechas a los mismos estudiantes, que en un $13 \%$ y $41 \%$, los motivan a la participación al gobierno escolar los docentes y directivos respectivamente; el porcentaje participativo entre niños y niñas, es de 
un $45,4 \%$ y $54,6 \%$, para los primeros y segundos. En general, tanto niños y niñas que participan en una postulación directa, presentan planes de gobierno en un $54 \%$ y hacen campaña política dentro de la institución en un $78 \%$. Es importante destacar que presentan entre una, dos, tres y cuatro planillas para la postulación, la que más se repite presenta dos, con un 79,1\%; en consideración que hay un bajo porcentaje de $4,1 \%$, que solo presenta candidatura única, contrastando que entre tres y cuatro, hay un porcentaje de 8,3 \% para ambos casos. En cuanto a las actividades que desarrollan durante el año de elección, encontramos: promoción de los derechos de la niñez, medioambiente, lectura, como también actividades recreativas y socioculturales.

Se constata entonces, que la escuela como forjadora de democracia, es el lugar propicio para iniciar el fomento de la participación paritaria en todos los estamentos donde puedan hacer mayor presencia tanto las niñas como los niños, utilizando los mecanismos constitucionales y legales, que dan paso a la contribución favorable de la participación.

En síntesis, la participación equitativa de mujeres/hombres en el poder, como en la toma de decisiones es clave para la superación de la desventaja social a la que ha estado advocada la mujer; coadyuvando para el desarrollo económico, para la vigencia de los derechos humanos, etc. Es decir, ninguna de las áreas estratégicas podría ser cumplida sin la participación política de las mujeres en igualdad con los hombres. Esto convierte a la participación política en una variable dependiente de cualquier política pública. 


\section{Colombia}

Entre muchos otros, Colombia tiene un reto de: garantizarles a más de 16 millones de niños, niñas y adolescentes las mejores condiciones para su desarrollo integral, asegurándoles aquellos derechos que la Constitución de 1991 y la Convención de los Derechos del Niño les han reconocido. El cumplimiento de estos derechos involucra que simultáneamente avancemos en su supervivencia, protección, participación y desarrollo, siendo la educación un eje central en este esfuerzo.

Todas las naciones han reconocido la educación como un factor esencial para que los niños, niñas y adolescentes sean incluidos socialmente, como también, para que obtengan igualdad de oportunidades. Así lo expresaron en las dos recientes conferencias de Naciones Unidas sobre Educación, la Declaración de Jomtiem (1990) y el Marco de Acción de Dakar (2000), al igual que en la suscripción de Desarrollo del Milenio (2002). A partir de ellas se han movilizado diversas organizaciones nacionales e internacionales para la consecución de la Educación para Todos (PNUD, 2012). Consecuentemente, UNICEF en el mundo y en América Latina ha impulsado iniciativas como Escuela Amiga que promueve la apropiación de los derechos de los niños, niñas y adolescentes en el ámbito escolar.

En Colombia se han desarrollado diversas iniciativas para garantizar el derecho a una educación de calidad; las cuales desde múltiples enfoques promueven que todas las niñas, niños y jóvenes tengan iguales oportunidades de aprender en forma activa, participativa, colaborativa, con alegría y buen trato; en ambientes saludables, que faciliten el desarrollo integral. Desde el Estado, en sus instancias nacional, departamental y municipal, existe un vínculo de corresponsabilidad con la sociedad y las familias, 
que se ha posicionado en el tema de la educación, como un ámbito estratégico para el desarrollo tanto humano como social; a través de procesos de planeación y gestión de políticas públicas educativas.

La guía Hacia una escuela de calidad, recoge las lecciones aprendidas en el desarrollo de la iniciativa Escuela Amiga de la Niñez, que impulsó el mejoramiento de instituciones educativas con un enfoque de derechos. Son ideas para la acción que complementan el esfuerzo del Ministerio de Educación Nacional, de las entidades territoriales y sus Secretarías de Educación con sus equipos de calidad; de las Instituciones Educativas con sus comunidades educativas y equipos de gestión y de todas las entidades públicas, privadas, no gubernamentales y de cooperación comprometidas con el mejoramiento de la calidad educativa (UNICEF, 2006, p.7).

En resumen, la presencia de agencias internacionales en Colombia como UNICEF, reforzadas por el Ministerio de Educación Nacional en lo relacionado a estudios dentro del contexto escolar, a través del enfoque de derecho, que promueven el buen trato, la convivencia, la participación van demarcando las abstracciones necesarias para tomar atenta nota y fortalecer los procesos de inclusión, desde la política pública.

\section{REPRESENTATIVIDAD POLÍTICA EN IGUALDAD DE GÉNERO}

Ha habido deficiencia, en lo representativo, a la igualdad entre los géneros, nace de la desigualdad y de la búsqueda de desactivación de las sociedades estamentarias; sin embargo, fueron los varones quienes dejaron por fuera a la otra mitad de la humanidad. Sin embargo, ellas fungieron a organizar su pro- 
pio camino y hasta ahora, se connota el movimiento de mujeres, como el de más trascendencia, desde el siglo XVIII hasta acá.

Tras haberse identificado las paradojas del discurso de la igualdad, en el siglo XVIII, hay que preguntarse por el siglo XIX. Ese siglo presenció en su primera mitad, y de la mano del Romanticismo, una respuesta reactiva frente a las posibilidades que abrió para las mujeres el discurso ilustrado de la igualdad (Cobo, 2008). Sin embargo, hay que decir que en el siglo XVIII los contractualistas no solo tuvieron la oportunidad de observar posiciones intelectuales coherentes con los ideales ilustrados de igualdad, sino también de polemizar con aquellos autores y autoras que exigían el cumplimiento de la universalidad para todos y todas las ciudadanas. Es decir, esta ilustración patriarcal fue interpretada por otra ilustración más universalista que asume que la igualdad y la libertad pertenecen a la humanidad en su conjunto y no solo a los varones (Cobo, 2008).

La búsqueda de la igualdad de género, en la representación, es un elemento central de una visión de la sostenibilidad en la cual cada miembro de la sociedad respeta a los demás y desempeña un papel que le permite aprovechar su potencial al máximo. La amplia meta de la igualdad de género es una meta social a la que la educación y las demás instituciones sociales deben contribuir. La discriminación de género está imbricada en el tejido de las sociedades. En muchas sociedades, las mujeres llevan la carga principal de la producción de alimentos y la crianza de los niños. Además, las mujeres a menudo son excluidas de las decisiones familiares o comunitarias que afectan a sus vidas y bienestar (UNESCO, 2014).

En esa medida entonces, la igualdad es un principio político y ético que germina en la ilustración y que tiene una base sóli- 
da en la noción de la universalidad. De manera tal, que ambos conceptos: universalidad e igualdad, presuponen una idea de una única humanidad y excluyen cualquier segregacionismo y jerarquización entre individuos y grupos. Estas nociones tienen un carácter normativo, pues señala aquello que es ética y políticamente deseable, que hombres y mujeres, blanco y negros, homosexuales y heterosexuales, etc... merecen la misma consideración social y política. El principal mérito político de las ideas de universalidad e igualdad es su capacidad de impugnación de las injusticias sociales y políticas. Ambas ideas constituyen poderosos principios de deslegitimación de cualquier relación fundada en privilegios (Cobo, 2008).

Hay que señalar la profunda contradicción que se desprende de un discurso, el de la igualdad, cuya vocación es la universalidad y, sin embargo, cuya aplicación práctica produce exclusiones de ciudadanía para diversos sectores sociales, entre ellos las mujeres, es decir, la mitad de la población.

Se connota entonces, que la representación política en condiciones de igualdad, es uno de los puntos que estudia Kymlicka (2010) en su obra Ciudadanía Multicultural, donde destaca el valor de la representatividad del grupo, le da valor a esta representación, ya que el sistema político es poco representativo, es una idea común, pero esta noción inherente a ella, raramente se explora con profundidad. Por tanto, la afirmación de que los grupos minoritarios no están suficientemente representados en el legislativo, parece presuponer que la gente únicamente puede estar representada por alguien de su mismo género, clase, ocupación, etnia, lengua (Kymlicka, 2010, p.192).

Entonces ¿por qué son tan importantes las características personales de los representantes? Hay varias razones por las 
cuales las características personales pudieran ser tan importantes; es decir, algunos expertos argumentan que las personas deben compartir determinadas experiencias o características para poder comprender verdaderamente las necesidades y los intereses de los demás. Si ello es así, un hombre blanco sencillamente no puede saber en qué consisten los intereses de una mujer o de un hombre negro: ningún tipo de reflexión o de comprensión, por muy profunda y sincera que sea, puede saltar las barreras de las experiencias (Phillips en Kymlicka, 2010, p.193).

De esa manera, no se trata de tipificar la representación, la solución no estriba en aceptar esas limitaciones, sino en combatirlas para crear una cultura política en la que las personas puedan y estén dispuestas a ponerse en lugar de los demás, así como comprender realmente ( $\mathrm{y}$, por consiguiente, a representar) sus necesidades e intereses desde el referente de derechos humanos. Esto debe exigir cambios en el sistema educativo, en los medios de comunicación y en el proceso político, para acercarlo en un sistema de democracia deliberativa.

Finalmente, tanto a nivel general como en el particular, ejemplificado este último en el espacio escolar, se requiere iniciar el nivel representativo de géneros, donde la comprensión de lo diverso se ajuste desde el concepto de derechos; que no sea una convergencia táctica, que sean concretizaciones de una representatividad que deliberadamente pueda tener puntos de encuentro y presencia, tanto hombres como mujeres.

\section{Política de reconocimiento como fusión de horizontes entre género}

El feminismo, el multiculturalismo, el nacionalismo y la lucha contra la herencia eurocéntrica del colonialismo son fenómenos 
que, aunque se encuentran emparentados, no deben ser confundidos. Su parentesco estriba en que tanto las mujeres, las minorías étnicas y culturales, así como las naciones y las culturas, ofrecen resistencia contra la opresión, la marginación y el desprecio, y de este modo luchan por el reconocimiento de las identidades colectivas, sea en el contexto de una cultura mayoritaria o en el de la comunidad de los pueblos. Se trata de movimientos de emancipación cuyos objetivos políticos colectivos se definen en primera instancia en clave cultural, aun cuando siempre estén en juego también desigualdades de carácter económico así como dependencias de naturaleza política (Habermas, 1999, p.197).

Congruentemente, durante las últimas tres décadas, la conflictividad social ha dejado de estar centrada en las cuestiones obreras y luchas de clases, para instalarse nuevos movimientos sociales que, gracias a la distribución desigual de la autoridad que demuestra insuficiencia institucional y así mismo distribuye desigualmente reconocimiento, hace que nuevos movimientos sociales de ecologistas, género, jóvenes y etnias integren a los nuevos sujetos en búsqueda tanto de transformaciones sociales como de un capital simbólico, que se evidencia en el caso de las mujeres en "reclamos" que no necesariamente tienen que ver con vínculos laborales o económicos sino de lograr una visibilización de su existencia y reconocimiento (Femenías, 2007, p.23).

Para ello, Bauman (2003) lo integra al multiculturalismo y lo distingue así: por un lado multiculturalismo diferente y por otro crítico; el primero lo define como creador y sostenedor de la cultura que poseen las élites e imponen a los demás, y el segundo como una aproximación plural este que debe sostenerse. Para efectos de este trabajo, será nuestra referente. 
No obstante, el multiculturalismo crítico se aproxima más al reconocimiento de la diferencia entrando un poco al campo intercultural, y es preciso lo que nos ilumina Leciñana Blanchard (2004) a través de dos distinciones fundamentales:

1) Políticas de la identidad y reconocimiento, en la diferencia, movimientos sociales que proponen cambios a partir de la diferencia.

2) Formas de vida diferentes: conserva tradiciones particulares y derechos de las minorías, sean sexuales, culturales, o de otros grupos sociales, invisibilidades.

Ahora bien, desde las promulgaciones universalistas de la libertad, igualdad y solidaridad, en un segundo orden se ofrecen las propuestas fundamentales del multiculturalismo. A partir de la diferencia que en la década del sesenta fue entendida y valorada, situación que no sucedía antes del giro del honor a la dignidad, la diferencia atraviesa la categoría sexo-género, como a su vez las variables etnia, clase. De esta manera una mujer, que además sea indígena, por consiguiente en desventaja social, hace que su participación dentro de espacios sociales, educativos y laborales puedan establecer en la actualidad una relación negativa en cuanto a la posibilidad de la participación directa en procesos democráticos.

En ese orden de ideas, desde la diferencia se crean identidades, las cuales se activan en la búsqueda del reconocimiento. Aquí Taylor nos da un valioso aporte: "Somos formados por el reconocimiento del otro, de esta manera el falso o poco, daña o conlleva a una falsa imagen de sí" (Taylor, 1993, p.11). Es lo experimentado en la época patriarcal, en la cual a la mujer desde lo externo se le creaba una imagen que ha sido difícil de borrar, permaneciendo aún en la actualidad con todas las reivindicaciones del feminismo. 
De esta manera el discurso del reconocimiento se ha vuelto familiar en dos niveles:

1. En la esfera íntima: Donde comprendemos que la formación de la identidad y del yo tienen lugar en el diálogo sostenido.

2. En la esfera pública: Donde la política del reconocimiento igualitario ha llegado a desempeñar un papel cada vez mayor. Aquí en la política de reconocimiento con dos cambios principales, que se han dado a partir del tránsito del honor a la dignidad y el concepto moderno de identidad hizo surgir la política de la diferencia.

No obstante, como en el contexto intercultural surge una exigencia poderosa, de acordar igual respeto a las culturas que han evolucionado de allí, el rasgo decisivo de la vida humana es su carácter dialógico para la construcción de la identidad y del reconocimiento. De hecho, el reconocimiento -según Taylor-debe ser en dos niveles:

- Respeto a la identidad, independientemente de la raza, sexo, etnia;

- Respeto a aquellas prácticas o modos de ver el mundo.

Así, la mujer ha ido logrando reconocimiento de su identidad sexual, étnica, en consideración también al rol que le pertenece y que ya es necesario asumir, desde sus logros en una sociedad que continúa siendo perpetrada por lo masculino e individualista.

De otro modo, se puede considerar que el feminismo no es asunto de una minoría. Se dirige contra una cultura dominante que interpreta la relación entre los sexos de un modo asimétrico que excluye la igualdad de derechos. La diferencia de las situaciones de vida y experiencias específicas de cada sexo no en- 
cuentra ni jurídica ni informalmente una consideración adecuada: ni la comprensión que en clave cultural las mujeres tienen de sí mismas, ni su contribución a la cultura común, encuentran su debido reconocimiento. Bajo las definiciones dominantes tampoco cabe articular de manera suficiente las necesidades femeninas. Por ello, la lucha política por el reconocimiento se inicia como una lucha por la interpretación de las aportaciones y de los intereses específicos de las mujeres. En la medida en que esa lucha tiene éxito, cambia junto con la identidad colectiva de las mujeres también la relación entre los sexos y acaba directamente afectada la comprensión que los varones tienen de sí mismos. El catálogo de valores de la sociedad en su totalidad se pone en discusión; las consecuencias de esta problematización penetran hasta en la esfera privada y afecta también los límites establecidos entre las esferas pública y privada (Habermas, 1999, p.197).

Con estas consideraciones presentes, ciertos cambios históricos fueron necesarios para hacer posible la política del reconocimiento. En primer lugar, la caída de las jerarquías sociales, basadas en el honor de las sociedades testamentarias. El honor se vincula intrínsecamente a la desigualdad: para que algunos tengan honor, otros no deben tenerlo. En cambio, en una sociedad democrática, solo hay cabida para el concepto de dignidad, en un sentido universalista e igualitario. A partir del siglo XVIII, se intensificó la importancia del reconocimiento como interpretación de la identidad individualizada. Es ser fiel a uno mismo (Femenías, 2007, p.124).

Reconocer la competitividad parece una grave medida mimétrica entre géneros. Cuando lo masculino, se seguirá en la plataforma de la lucha del poderoso y el débil. Se tendría que 
superar la dialéctica del que se siente superior e inferior, en una lógica más nietzscheana de mujeres de espíritu dionisíaco. Se debe ir más allá de la lucha y generar caminos femeninos de diálogo, pues la seguridad que se asume desde el mundo femenino, es solidaridad, comprensión, fortaleza, paz y confianza en sí misma. Éticamente es preferible escuchar y ser escuchada, que competir reconociendo jerarquías (García-Torres en Hierro, 1995, p.128).

El problema es que se sometan a las lógicas masculinas de competencia, se desintegran, dejan la pasividad y entran en una competencia, pero también tendríamos que pensar en una forma de integrarnos en la cultura patriarcal, que contenga la calma, que no nos ubique a las mujeres fuera de juego; ya que lo imperante en occidente es la competencia y el ataque. ¿Cómo podemos las mujeres jugar en la competencia? (García-Torres en Hierro, 1995, p.125).

Finalmente, identificada la lógica del desafío por el reconocimiento en que ha estado inmersa la mujer y validando la desventaja social en la cual se ha encontrado o se encuentra inmersa desde su apropiación como sujeto, además como participante de la política que había sido desvirtuada por su función reducida a la reproducción, a la unión marital y sus habilidades domésticas; pero que gracias a los logros de otras mujeres en el mundo, aunado al avance en las teorías de género, como en la política pública, hoy es posible orientar nuevas acciones dentro de su liderazgo, valorando humanamente sus funciones iniciales, siendo inherentes a ellas y las construidas a partir de las circunstancias actuales. Para así por fin abrir nuevos espacios que determinen una fusión de horizontes, donde aprendemos 
a desplazarnos en un horizonte más vasto, en la utilización de nuevos vocabularios de comparación, importancia de entendernos intersubjetivamente en la igualdad pero aceptando las diferencias inherentes al ser humano dentro de cualquier cultura a escala mundial como en cada sociedad individual (Gadamer en Taylor, 1993, p.28).

\section{Género y educación, desde la autodesignación femenina}

El feminismo es un fenómeno social, surgido en el siglo XVIII, tematizado conceptualmente en la llustración y, al mismo tiempo una de las manifestaciones reflexivas más significativas de la modernidad. François Poullain de la Barre, Mary Wollstonecraft, Diderot, Condorcet, Von Hippel, entre otros, exigieron coherencia epistemológica y política a esa llustración patriarcal, que hacía proclamas igualitarias. Estos autores y autoras, definieron la subordinación social de las mujeres como resultado de prejuicios que se remontaban a la noche de los tiempos (Cobo, 2008, p.28).

La consolidación del feminismo viene a unir un conjunto de voces de mujeres en todo el mundo, en la búsqueda de la igualdad como principio político y ético que germina con la llustración y tiene una base sólida en la noción de universalidad. Ambos conceptos, universalidad e igualdad, presuponen normativamente la idea de una única humanidad y excluyen cualquier segregacionismo y jerarquización entre individuos o grupos. Estas nociones tienen un carácter normativo, pues señalan aquello que es ética y políticamente deseable: todos los individuos en cuanto a tales (hombres, mujeres, blancos y negros, homosexuales y heterosexuales) merecen las mismas consideraciones políticas (Cobo, 2006, p.29). 
La desproporción que ha existido históricamente en relación a la mujer, una heterodesignación que ha sido marcada por la sociedad patriarcal pero que conlleva a constituir una autodesignación que la hace asumir un compromiso con ella y con su realidad sociocultural, modificándola, asumiendo así un nuevo rol (Amorós, 1991; Pateman 1998; Femenías, 2007; Cobo, 2006).

Lo experimentado en la época patriarcal, donde la mujer desde lo externo se creaba una auto-imagen, difícil de borrar aún en la actualidad con todas las reivindicaciones del feminismo, encontramos que se siguen perpetuando acciones violentas contra ellas. Un ejemplo en aquella época fue cuando Olympe de Gouges (1791), propuso los derechos de la mujer y la ciudadana, lo cual expresaba la exclusión sufrida no tanto por modelos de antiguo régimen, sino por sus compañeros progresistas e igualitaristas.

En ese orden, la teoría feminista ha sostenido que las mujeres en las sociedades patriarcales, fueron inducidas a adoptar una imagen despectiva de sí mismas. Internalizaron una propia imagen de su inferioridad (heterodesignaciones), de modo que aun cuando se supriman los obstáculos a su avance, en ocasiones las limita para aprovechar las nuevas oportunidades (autoasignación). Se ha establecido un punto análogo en relación con las personas de color, debido a que la sociedad blanca les proyectó durante generaciones una imagen deprimente de sí mismas; según esta idea, su propia autodepreciación se transforma en uno de los instrumentos más poderosos de su propia opresión. Coincide con lo anterior, lo que en 1960, en Estados Unidos pusieron muy de moda el lema The Black is beautifull como referente autoafirmativo para resignificar su diferencia, a partir del color de su piel (Taylor, 1993, p.11). 
Solo hasta el siglo XVIII, las mujeres visibilizaron la heterodesignación patriarcal; de allí que todos los derechos obtenidos, sobre todo el del sufragio y la educación, hicieron parte de los movimientos sociales, aunque en la actualidad los países constitucionales basados en la igualdad de derechos, existen para ambos sexos, mecanismos subterráneos para reproducir la desigualdad de género. Estos mecanismos desembocan inevitablemente en lo que el feminismo ha tematizado como "techo de cristal". Es esta una metáfora acuñada por el feminismo para explicar precisamente las dificultades que existen entre el tránsito de los derechos formales y los derechos materiales. En ese tránsito aparecen mecanismos difíciles de visibilizar que obstaculizan el ejercicio de la ciudadanía para las mujeres apartadas de los espacios de poder y, por ello no es fácil detectar esos filtros que operan subterráneamente para expulsar a las mujeres de los espacios de poder, recursos y jerarquía (Cobo, 2006, p.43).

No sería posible considerar que en la contemporaneidad, aún existan sesgos al género, no solo para inclusión en lo político, sino también en la educación; es por ello que se considera significante, no solo para hombres sino para mujeres, y aunque a estas hayan sido logradas plenamente a través de reivindicaciones históricas, a partir de sus propias iniciativas la escuela y las relaciones sociales que se desarrollan en su interior, en distintas direcciones, constituyen una herramienta de socialización significativa. En la escuela entra en funcionamiento una gran variedad de relaciones sociales entre profesorado y alumno, entre niños y niñas, entre chicos y chicas.

Finalmente, el aporte que ha hecho la teoría feminista en el desarrollo del género a través de la educación, es que por ser una teoría crítica, desde allí se iniciaron procesos de transforma- 
ción en relación histórica a los que el imaginario ha adoptado hacia lo femenino y que las autodesignaciones de la incorporación de la mujer en el entramado educativo, contribuye a mejorar sus propios desarrollos y por ende colectivos.

\section{METODOLOGÍA}

Se trata de un proyecto de tesis doctoral, aplicado en el departamento del Atlántico, en ocho Instituciones Educativas en los municipios de Malambo, Ponedera, Tubará y la ciudad de Barranquilla. Se ocupó la metodología cualitativa, a través de un estudio de casos; implementando las técnicas de investigación como entrevista a profundidad, grupos focales y observaciones documentales. Las dos primeras, se realizaron con directivos, docentes, líderes y voceros estudiantiles; la tercera, a documentos legales, bases de datos, como a su vez, a revisión de textos que integran la teoría feminista, interculturalidad y participación femenina.

Las decisiones en torno a los escenarios institucionales, fueron ocho instituciones educativas y en cada una de ellas, el requerimiento que hicieran parte de la red pública, educación media, mixtas, con la mitad de personeras estudiantiles electas, y finalmente, que se pudiera acceder a los directivos, docentes del área de Sociales y voceros estudiantiles (ver Tabla 7).

Tabla 7

Características de instituciones y actores/as, que hacen parte del estudio

\begin{tabular}{|c|l|l|}
\hline $\mathbf{N}$ & \multicolumn{1}{|c|}{ Características de Instituciones } & \multicolumn{1}{|c|}{ Características de sujetos } \\
\hline \multirow{2}{*}{1} & $\begin{array}{l}\text { Instituciones públicas } \\
\text { Mixtas }\end{array}$ & Directivos docentes \\
& $\begin{array}{l}\text { Educación media } \\
\text { Personeras estudiantiles electas }\end{array}$ & $\begin{array}{l}\text { Docente ciencias sociales } \\
\text { Estudiantes líderes personeras }\end{array}$ \\
& Diversidad geográfica cultural \\
& (Urbano, semi-urbano, rural-étnico, rural-costero) & Voceros estudiantiles \\
\hline
\end{tabular}

Fuente: Adaptación a partir de identificación de actores/as y escenarios 
La definición en cuanto al género de los/las actores participantes de estudios se tomaron dos tipos de decisiones: inducida y aleatoria. La primera, en torno a la personería estudiantil, la cual consideró necesaria la presencia de manera paritaria el número de personeras y personeros del total de las instituciones educativas participantes. La segunda se refiere a los demás actores participantes del estudio, como son, los directores, profesores y voceros estudiantiles de los cuales no interesaba su adscripción de género. Se procedió seguidamente a la codificación de instituciones y actores para salvaguardar sus identidades. A continuación se especifican (ver Tabla 8).

\section{Tabla 8}

Codificación institucional y de los/las actores participantes del estudio

\begin{tabular}{|c|c|c|c|c|c|}
\hline Lugar & Institución & Directores/as & $\begin{array}{l}\text { Personeros/as } \\
\text { estudiantiles }\end{array}$ & Profesores/as & $\begin{array}{l}\text { Voceros/as } \\
\text { Estudiantiles }\end{array}$ \\
\hline \multirow{2}{*}{ Barranquilla } & IE 11 & D 11 & PE 11 & P 11 & VE $11 \mathrm{~N}$ \\
\hline & IE 12 & D 12 & PE 12 & P 12 & VE $12 \mathrm{~N}$ \\
\hline \multirow{2}{*}{ Malambo } & IE 21 & D 21 & PE 21 & P 21 & VE $21 \mathrm{~N}$ \\
\hline & IE 22 & D 22 & PE 22 & P 22 & VE $22 \mathrm{~N}$ \\
\hline \multirow{2}{*}{ Tubará } & IE 31 & D 31 & PE 31 & P 31 & VE $23 N$ \\
\hline & IE 32 & D 32 & PE 32 & P 32 & VE $31 \mathrm{~N}$ \\
\hline \multirow{2}{*}{ Ponedera } & IE 41 & D 41 & PE 41 & P 41 & VE $41 \mathrm{~N}$ \\
\hline & IE 42 & D 42 & PE 42 & P 42 & VE $42 \mathrm{~N}$ \\
\hline
\end{tabular}

Fuente: Adaptación a partir de los listados de los/las instituciones y los/las actores participantes del estudio

En ese sentido, los/las actores participantes del estudio, que en total fueron ochenta y seis, entre directores/as, profesores/ as, como también, personeros/as y voceros/as estudiantiles, de ellos el $59 \%$ pertenece al género femenino, el $41 \%$ al masculino. Se consideran a continuación, las variables género y edades; lo cual, con el soporte del software estadístico del SPSS, contribuye a su interpretación. 
Hay una participación paritaria, en torno a los personeros/as estudiantiles. No ocurre así con los directores/as, profesores/as y voceros estudiantiles, que al no tener preferencia inicial por su género, se encontró que intersecta la inclusión femenina en un $63 \%$, entre las profesoras y voceras estudiantiles, lo que declina en la presencia de las directoras, decayendo a un $37 \%$; ahí existe mayor presencia masculina, en un $63 \%$. Hay correlación con las estadísticas de inclusión de género en cargos directivos y políticos, detallados en los antecedentes de contexto; donde confirma la no existencia de paridad participativa, entre géneros (ver Gráfico 2).

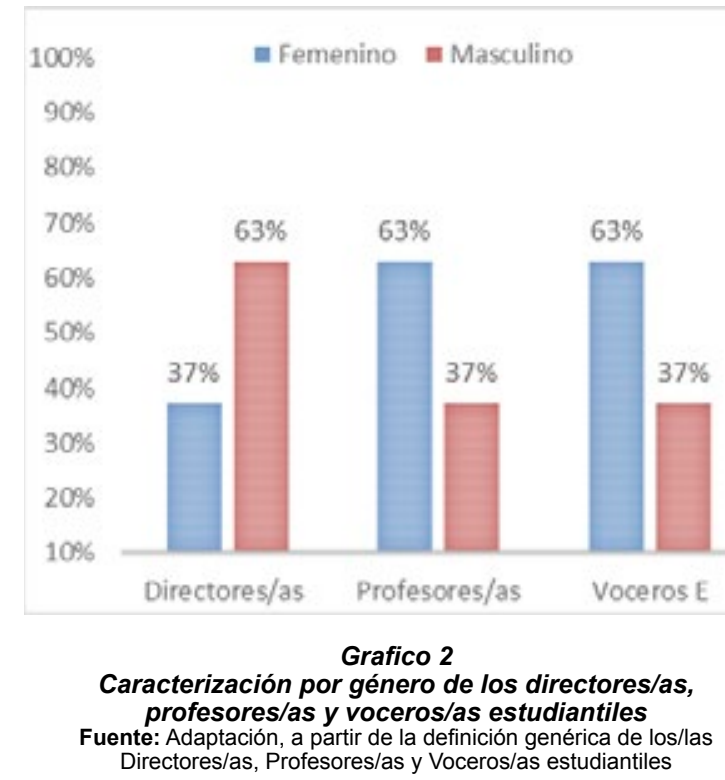

En cuanto a distribución etaria de los participantes del estudio, se encontró que existe una diferencia de dos años, entre los/ las personeros/as y voceros/as estudiantiles considerando que los primeros están en la etapa final de sus estudios medios, y los segundos pertenecen a los diferentes grados de esos estudios. Las edades que más se repiten son los diecisiete y catorce años 
respectivamente. Teniendo en cuenta que, en el caso de los/las personeros/as, hay un número total de ocho entrevistados/as; y los/as voceros/as, hay sesenta y dos, al darse aplicaciones de ocho grupos focales (ver Tabla 9).

Tabla 9

Distribución etaria de los/las personeros/as y voceros/as estudiantiles

\begin{tabular}{|c|c|c|}
\hline Estadísticos & Personeros/as & Voceros/as Estudiantiles \\
\hline Media & 17 años & 14 años \\
\hline Moda & 17 años & $13-15$ años \\
\hline Mediana & 17 años & 14 años \\
\hline
\end{tabular}

Fuente: Adaptación a partir de datos obtenidos a través del programa SPSS

Así mismo, la distribución de edades, entre los/las directores/ as y profesores/as, que hacen parte de los estudios, fluctúa entre los cuarenta y dos y cincuenta y dos años, prevaleciendo las repeticiones en los cuarenta y dos, respectivamente. En cuanto a la media y la mediana se mantiene en los cincuenta y dos años (ver Tabla 10).

Tabla 10

Distribución etaria de los/las directores/as y profesores/as

\begin{tabular}{|c|c|c|}
\hline Estadísticos & Directores/as & Profesores/as \\
\hline Media & 52 años & 52 años \\
\hline Moda & 42 años & 42 años \\
\hline Mediana & 52 años & 52 años \\
\hline
\end{tabular}

Fuente: Adaptación a partir de datos obtenidos a través del programa SPSS

En definitiva, se logra abstraer de los escenarios y sujetos, que integran el estudio que las definiciones de cada uno de ellos, ha favorecido para la obtención de las interpretaciones necesarias que en definitiva lograron armonizar la aplicación empírica en conjunto con los aspectos contextuales y teóricos de este estudio. Ahora se continúa en los parágrafos cinco y seis, que da paso a los resultados y principales conclusiones del estudio. 


\section{POLÍTICAS PÚBLICAS Y SU EFECTIVIDAD EN LA PARTICIPACIÓN FEMENINA}

Lo actitudinal sobresale aquí, en relación a quienes tienen injerencia en la política pública a favor del desarrollo participativo de la mujer coinciden los/las D, P, VE, (directivos, profesores, voceros/as estudiantiles) que hay una deficiencia en ello; en cambio, los/las PE (personeros estudiantiles), resaltan los logros de la política pública de manera simbólica, en su libre expresión y estatus social, aunque los/las VE, manifiestan un sentido crítico de la política pública y lo requerido de la paridad en la participación.

De esa manera; manifiestan los/las $D$ y $P$, que no son suficientes los programas en equidad de género, por parte de la política pública gubernamental a nivel local y departamental; de esa manera sostiene el P42, que no hay ejecución de programas de ese tipo. Coinciden los $\mathrm{P}$ y $\mathrm{D}$, que sí hay programas en torno a la equidad de género. Así mismo, que en la IE 2, sí hay, pero son intermitentes, solo para llenar requisitos. No obstante, solo los/ las $D$ sostienen que en la IE21 y 42, también son intermitentes, aunque el P42 había manifestado que no hay implementación. A continuación en la voz de los actores, se constata lo anteriormente expresado. De la manera, que los programas no son suficientes, ya que en algunos casos, son esporádicos y poco inclusivos: "Existen algunos programas adscritos a la Secretaria de Salud del Distrito, que de vez en cuando traen algunas acciones acá. En todo caso son esporádicas y no son suficientes. Se dedican a promoverla con actividades aisladas" (P11). "Sí, sí, claro que sí, nosotros estamos viendo cómo la administración actual, la alcaldía está promoviendo muchos programas que benefician a las mujeres, eso nos tiene muy satisfechos, pero falta mucho todavía" (P12). 
De otro modo, manifiesta la inexistencia de programas en beneficio del desarrollo femenino, sobre todo hacen la demanda en educación sexual y reproductiva; tiene que ver con uno de los lugares denominados en este estudio, como rural-étnico. En palabras del profesor de Ciencias Sociales: "No he visto; y precisamente ayer hablaba con unas estudiantes que me decían: 'oiga profe acá por qué no dan este... la cátedra de educación sexual no se dá'. 'Y fíjate que ese tema que tú me tocas de la diferencia de género', también me decía uno, y hay temas que de pronto se deben tocar en unas asignaturas y hay cosas que de pronto el gobierno debe de revisar a ver si se están dando en las instituciones o no, que son muy provechosas para nuestros alumnos" (P42).

En cuanto a lo que conceptúan las/los PE en relación a la efectividad de las políticas públicas a favor del género femenino, los primeros lo definen en aspectos que sobresalen en la participación política, y las segundas, reivindicación en igualdad de oportunidades, libre expresión y estatus social.

En ese sentido, los PE exaltan la favorabilidad de la política pública, en la integración de género sustentada en la mayor participación política y en cargos públicos a la mujer. En sus palabras: "Sí, he visto muchas mujeres así, no sé si es en el congreso o algo que luchan por las condiciones sociales y cosas de la mujer, entonces sí he visto que pueden hacer algo por las mujeres" (PE41). "La política pública para la mujer es muy importante porque simplemente si el hombre también tiene que ejercer cargos públicos a nivel nacional, la mujer también puede porque la mujer es un miembro importante de la sociedad" (PE32).

Entre tanto, hay unificación de criterios; las PE dicen que parte del beneficio desde la política pública, añade a logros mayores como la libertad de expresión y el estatus social. En las líneas 
que siguen, se confirma en las expresiones de las PE: "Claro que sí, porque nos estamos dando cuenta de que realmente una mujer también es importante, a nivel social, no solamente los hombres" (PE12). "Sí, uno de los beneficios que ninguna mujer por más fea que diga que es, siempre se va ver elegante en cualquier lugar y más si es una mujer de libre expresión, que le gusta expresarse fácilmente y ante un público, más rápido" (PE21).

En cuanto a la efectividad de la política pública, que puede cobijar a hombres y mujeres los/las PE aluden que se equiparan, dentro del marco de la igualdad, ya que se tienen las mismas capacidades. En voz de las personeras estudiantiles: "Los beneficios son iguales, van iguales entre el hombre tanto la mujer porque estamos haciendo las mismas cosas, capaces de hacer lo mismo" (PE11). "Bueno yo creo que es un tema en lo que ellos no entran muy a fondo porque es bastante controversial, pero tampoco lo niegan o tampoco lo hacen tan complicado" (PE11). En voz de los personeros estudiantiles: " ¿Beneficios como hombre? pues yo creo que no, porque ya todo lo que hacen los hombres, las mujeres también lo pueden hacer, entonces, no creía que tendría beneficios" (PE41).

En otro sentido, los/las VE sustraen cuatro dimensiones en relación a la suficiencia de las políticas actuales de participación y la armonía en la práctica institucional. Primera: aceptación del cumplimiento de las políticas. Segunda: insatisfacción con la aplicabilidad de las políticas participativas, de lo que subyace mayores niveles para acceder a la participación (IE 3). Tercera: extrapolación de la política general, ligada al clientelismo y corrupción (IE 2). Cuarta: búsqueda de la paridad en la participación. Dejando claro que existen avances particulares de inclusión participativa institucionalmente. 
Primera: es el cumplimiento de la normativa, en relación a la constitución y en relación al consejo estudiantil. En voz del VE 122: "Si en el colegio se ha tratado de cumplir con todas las reglas que hay en el manual de convivencia, o sea, en la constitución, de que hay que tener un consejo estudiantil, siempre se ha llevado como ese orden de tratar de cumplir". Aunque identifican el cumplimiento, por otro lado, manifiestan la insuficiencia respecto al grado motivacional y apoyo en la participación, así lo expresa el VE427: "Yo pienso que no, no es suficiente; necesitamos como un apoyo más grande y una motivación un poco más mayor que la que tenemos ahora".

Segunda, hay insatisfacción entre la normativa existente y su aplicabilidad, dentro de los y las estudiantes que participan activamente, debido a que consideran que están dispuestos a aportar en la solución de las situaciones complejas que tiene la institución y en ocasiones no se le facilitan los espacios necesarios. Así lo consideran los VE: "Sí creo que necesitamos espacios para nosotros, sí se necesita un espacio ya que nosotros somos líderes y tenemos que así sea cada un mes aportar las ideas o si siquiera la problemática que se está viviendo en la institución" (VE316). "Como dijo la compañera, tenemos pocos espacios, de pronto los problemas, lo que se le ha entregado a la señora rectora, no han sido acatadas" (VE318). "Diría que sí, debería haber más participación en todos los puntos, tanto en este como en el estudiantado" (VE322).

Tercera, evidenciando el clientelismo y la insuficiencia en cuanto al compromiso de consciencia colectiva en lo que representa el voto y las posibles consecuencias en la falta de políticas públicas razonables y que sean asequible a todos y a todos los ciudadanos. Ahora bien, en palabras del VE2111: "Creo que no, 
no son eficientes porque los alcaldes, toda la politiquería es una promesa, tras promesa, tras promesa, entonces, todas las cosas quedan como hasta la mitad o no terminan su curso y creo que a este municipio, hablo de él porque aquí es donde vivo, creo que le falta mucha responsabilidad a los alcaldes que siempre se lanzan y eso, y a la hora de lanzarse eso son promesas, son como 10 mil promesas y cuando quedan no hay ni media realizada, entonces creo que le hace falta mucho".

Y cuarta, en cuanto a la idealización de la paridad, como superación del treinta por ciento de la ley de cuotas, la proponen como política incluyente a la mujer en el espacio público, en su totalidad, hay unidad de criterio. La enmarcan en la identificación con los derechos e igualdad de oportunidades (IE1); como contraposición a la discriminación que aún segmenta a la mujer para el desarrollo de sus capacidades (IE3). Sin embargo, en las IE2 manifiestan que aún hay ausencia de la autodesignación de la mujer, lo cual ejemplifican con la inasistencia en las convocatorias de vocerías estudiantiles. En sus propias palabras: "aún pienso que es poco porque me parece que si somos todos iguales, es igualdad, o sea 50 y 50 , entonces tenemos que ser iguales todos, así como dicen que somos iguales todos ante la ley, entonces me parece que todo debería ser igual, entonces 50 y 50 tiene que ser" (VE121). "Porque si le damos el 30 \% esas estiraditas son una discriminación, todavía se le está seleccionando a la mujer, si le damos el 50 le estamos dando el mismo valor que a los hombres" (VE311). "El consejo estudiantil tiene varias mujeres lo que pasa es que no vienen, y como aquí hay un representante de cada grado, entonces el consejo estudiantil cada curso tiene su representante, lo que es 6-A, son 4 sextos, creo que son 4 séptimos, 4 octavos, 4 novenos" (VE224). 
En definitiva, en cuanto a la política pública y su efectividad, existen opiniones encontradas; por un lado los D, P y VE, sostienen que aunque existen son insuficientes; contrastada con las expresiones de los/las PE, quienes sostienen que se han beneficiado desde la participación política y las reivindicaciones desde la libertad de expresión y estatus; aunque ambos convergen en que la igualdad es un posicionamiento de la política pública y es favorable. Finalmente, los/las VE, dan unos apartes importantes en cuanto a la participación estudiantil institucional que tiene una tendencia de aceptación del cumplimiento de la normativa; además, insatisfacción de la aplicabilidad de la política participativa y la extrapolación de la participación política en general ligada a la corrupción, el clientelismo sosteniendo la búsqueda de la paridad participativa como una plataforma para mediar en la igualdad, pero con la autoconsciencia y autoasignación de las mujeres. Lo que indica que existe un nivel de procesar la realidad externa aunada a la insuficiencia de la política pública, a favor de la inclusión femenina; son desafíos pendientes, tanto dentro como fuera de la institución.

\section{Reconocimientos institucionales de la participación femenina}

En cuanto a los reconocimientos que reciben los/las líderes estudiantiles, tanto los/las PE como los/las VE coinciden en que los reconocimientos los reciben mayormente de sus pares (estudiantes), debido, a que hay un histórico acumulado nulo, de parte de los/las D y $\mathrm{P}$; los incentivos los reciben solamente en méritos académicos y culturales. Aunque los/las VE sostienen que realizan el trabajo participativo, por algunas convicciones y los deseos de hacer aportes tanto institucionalmente, como, en el país, y que es valioso sentir el reconocimiento, cuando los/ las estudiantes les solicitan algunas gestiones y son tenidos en 
cuenta como líderes. A continuación en las voces de los P y VE, respectivamente.

De esa manera, los reconocimientos que obtienen los/las PE, son manifestadas en medio de la interacción que tienen con el estudiantado en general; ellos son quienes más destacan su labor. A diferencia de los docentes y directivos, que muy mínimamente dan algunos reconocimientos aunque sean verbales. En voz de los/las PE: "Para mí el mejor reconocimiento que hay sea que me digan, muy bien, te felicito, lo hiciste excelentemente" (P21). "Pero por parte de los profesores nunca he tenido algún reconocimiento" (P31). "Pues de parte de los estudiantes sí lo he sentido, los estudiantes siempre me han apoyado, jeeh! desde el momento de la votación se notó que me apoyaban y que podía contar con ellos completamente" (P31).

Entre tanto, los/las VE expresan que en el nivel del liderazgo estudiantil no han recibido ningún reconocimiento. Sin embargo IE21 e IE42, manifiestan que en nivel académico y cultural, sí han recibido reconocimientos. Sobresale un concepto que, dentro del liderazgo no es importante que se le reconozca, más bien es un trabajo que permite dar aportes para que haya cambios sociales (IE12). En definitiva, emerge un reconocimiento que es tácito, lo cual es experimentado cuando es presentado ante el estudiantado. Aunque los reconocimientos no se relacionen con la participación política entre los líderes estudiantiles, sí se aprecia cuando se destacan por méritos académicos y en áreas como la cultura.

En el primer caso, sostienen que no han tenido reconocimientos. En voz de los/las VE: "Yo pienso que no hemos tenido ningún reconocimiento de los profesores" (VE223). "Hasta el momento 
ninguno" (VE2114). "Por mi parte, yo creo no hemos obtenido ningún tipo de reconocimiento, creo que aquí ninguno presente por estar participando en las actividades de la vocería estudiantil" (VE427). En el segundo, por méritos académicos: "Yo o sea en el cargo así como vocera o representante del salón, no he recibido ningún premio, por estudiar sí, por méritos propios míos sí, pero de que esté ayudando al salón o de que esté haciendo algo por el salón y me hayan reconocido algo, no" (VE2111). Y tercero, cultural: "Creo que aquí todos han participado en carnavales, entonces que la reina, que esto, que aquello, que el baile, entonces sí te dan como un cartón de reconocimiento, que ganó y eso" (VE425).

Finalmente, otros/as opinan, que no hacen su trabajo de participación para que se les reconozca, sino, por ser un aporte a mejorar la institución, el país y también dentro de sus compañeros estudiantes, en los que son reconocidos por sus acciones de liderazgo participativo; en sus propias palabras: "Pues uno de todos modos no va con el objetivo de reconocer algo, sino de mejorar la institución o la ciudad, el país; desde mi punto de vista yo no voy con lo que me reconozcan que he hecho algo o que ella fue la que nos logró digamos así independizarnos o cosas así, sino que mejorar, siempre uno va con el objetivo de mejorar y siempre lograr cosas positivas para la comunidad, si ya nos reconocen algo bienvenido sea" (VE121). "Yo pienso que el reconocimiento es la satisfacción de uno sentirse útil y pues previo a la elección, nos llaman acá al patio salón y nos presentan a toda la comunidad" (VE416).

En suma, aunque no exista un comportamiento definido para la motivación para realizar reconocimiento al liderazgo político estudiantil como tal, de los PE y VE subyacen que sí lo hay por 
méritos académicos y representaciones del nivel cultural. Aunado a la visibilidad que brinda el estudiantado en general, lo cual también es un aspecto relevante en el reconocimiento que se destaca en el entramado institucional. Que finalmente, hay un contraste en el cual, manifiestan los/las VE, que los reconocimientos fundamentales existen en el esfuerzo personal y búsqueda de la transformación a partir de su liderazgo en el nivel institucional y territorial, es su fin último, por lo cual manifiestan que no les afectan los des-reconocimientos del nivel directivo.

\section{CONSIDERACIONES FINALES}

En este ítem, las conclusiones se desarrollarán en dos sentidos; por un lado, de lo abstraído de los documentos legales nacionales; y por otro de lo encontrado en el entramado institucional, asociado a la injerencia de la política pública, en la participación femenina que permite finalmente hacer el contraste de lo legal a lo real en cuanto a la participación femenina en el contexto escolar.

En el primer caso: considerando lo legislado en cuanto a la participación femenina en Colombia, se presentará en dos momentos. a) Se concluye, a partir del aporte de las legislaciones definidas en los análisis.

\section{Aporte de la legislación colombiana a la participación femenina}

Para el análisis documental, se eligieron ocho legislaciones ${ }^{8}$, iniciando por el principio universal de derechos humanos, en la integración y reconocimiento a la igualdad y dignidad humana a nivel universal, como a su vez, centrado en la legalidad colom- 
biana a favor de la incorporación de lo femenino en lo educativo, político y sociedad en general. Tuvo que ver, con los intereses investigativos, los cuales se orientan en un espacio micro, como es el escolar; en contraste con lo que acontece desde la política pública, con favorabilidad de la mujer, en los ámbitos de la política y cargos públicos de poder. Consecuentemente, se abstrajeron de sus dictámenes, lo relacionado a: la igualdad, la participación social, discriminación positiva y reconocimientos que interconectan y arguyen para contrastar de lo legal a lo real en la participación de la mujer, a nivel general como en los espacios democráticos de la escuela.

En lo que concierne al principio de igualdad, a través de la indagación en las legislaciones elegidas se concluyen en tres núcleos, que dan fundamento legal, desde diferentes perspectivas y que facilitan soporte al trabajo empírico aplicado.

A continuación se presentan:

- Igualdad: dignidad, cultura y educación, considerando aquí lo legislado en los Derechos Humanos, la Constitución de 1991 y la Ley 115 -Ley de Educación-. En las dos primeras se identifican la dignidad igualitaria como máximo valor, que tanto en el nivel universal y nacional es una plataforma de avance para que la mujer se incorpore a la par de los hombres en la existencia sociopolítica. $Y$ en la última, la igualdad se delimita desde la educación como función social.

- Igualdad: oportunidad, en lo laboral y acceso a los servicios públicos, integrada por las Leyes 581 de 2000; 823 de 2003 y 1257 de 2008, garantes de la igualdad de oportunidad en cuanto a la participación activa de la mujer 
en la sociedad, en lo laboral, como también promueve el acceso a los servicios públicos, soportado en sus derechos individuales.

- Igualdad: participación política, correspondiente a las Leyes 1434 y 1475 de 2011, con la participación directa en política representativa, en un sentido de seguimiento en el Congreso de la República, por un lado; y la participación política en igualdad de condiciones, por otro. Se define en la anterior triada, que desde el vínculo de la igualdad, en lo educativo, como a su vez, en la inclusión laboral, en cuanto a los exámenes públicos de carrera administrativa, en cargos de poder como también es la igualdad de oportunidad en la vida pública y privada, en el acceso de los servicios públicos, definidos por los derechos individuales los que rigen de manera conjunta, en beneficio a la mujer, que marcan derroteros en la justicia social, donde prima el principio de igualdad.

La participación femenina, universalmente se establece desde los principios declarados en la proclamación de los derechos humanos; de ahí toman fuerzas las legislaciones intra-países, para avanzar en la inclusión femenina en la política, de diversas formas. En ese sentido, se abstraen tres núcleos, que fundamentados legalmente facilitan la interpretación de la participación de la mujer en cargos públicos de elección popular y también, en la delimitación escolar a través de las instancias participativas. Los núcleos identificados son:

- Participación: universal y nacional, en ese primer núcleo, se identifican desde la Declaración de los Derechos Humanos, la Constitución Política colombiana de 1991, y la Ley 115 de 1994, una definición sostenida de la par- 
ticipación libre y que posibilita la inclusión femenina. De esa manera universalmente, y también en el plano nacional, permiten que la mujer se incluya en los niveles políticos-sociales de participación. Delimitados en el espacio escolar como un microespacio, donde se funge como un laboratorio de ciudadanía, a través del ejercicio democrático de la personería estudiantil.

- Participación: femenina laboral, en este núcleo, lo legislado a partir de las Leyes 581 de 2000 y 823 de 2003; se define la paridad en los cargos directivos en los órganos de poder público, como a su vez, la igualdad de oportunidad en la participación en los diferentes aspectos de la vida pública y privada.

- Participación: política directa, en este núcleo, integrado por las Leyes 1434 y 1475 de 2011, se establecen unas definiciones en cuanto a la participación directa de la mujer en cargos públicos de poder y representación política directa, respectivamente. En ese sentido, hay unos dictámenes específicos en torno a lo funcional y definitivo del mínimo del $30 \%$ en los cargos a que se postulen las mujeres.

Cabe resaltar que es fundamental lo dictaminado en las Leyes 1434 y 1475 de 2011, lo cual no solo es fundamento para la participación, sino que determina promoverla y financiarla, respectivamente, para que las mujeres, sin distingo, puedan participar en cargos de las ramas del poder público y elección popular; de manera tal, que pueda haber mayor inclusión e injerencia en la política pública que beneficie al género femenino colombiano.

En síntesis, la inclusión de la participación ciudadana de la mujer, de manera universal y nacional, de forma directa en los 
cargos de representación política, en la vida nacional y el espacio escolar, es fundamental que esté normada, para que muchas más mujeres puedan interesarse en los niveles participativos. $Y$ que en el segundo espacio, sea un ejercicio que promueva la intencionalidad de su participación de manera pública.

Comprendiendo la discriminación positiva, que en el caso colombiano está delimitado en las Leyes 581 de 2000, 1434 y 1475 de 2011, hay niveles porcentuales mínimos, para la inclusión femenina, en el ejercicio de cargos públicos del nivel directivo, y de elección popular; con un mínimo de un $30 \%$, en ambos casos. Como a su vez, la comisión interparlamentaria, que exige la presencia femenina, de diecinueve congresistas; distribuidas en diez representantes a la Cámara, y nueve senadoras, respectivamente. De esa manera, como discriminación positiva, visibiliza la presencia de la mujer, aunque de lo legal a lo real, aún hay muchas brechas que impiden su cumplimiento. Se concluye que, aunque no son suficientes los porcentajes establecidos en las leyes antes descritas, debido a que lo ideal es la paridad en la incorporación femenina a cargos públicos de poder y elección popular, como a su vez en la comisión legal para la equidad, son formas que van indicando el camino y el interés gubernamental de contribuir a darle mayor visibilidad a la participación femenina en Colombia.

Finalmente, los reconocimientos a la diversidad en Colombia desde lo legal, que a diferencia de muchos países de América Latina, este país tiene cambios de la Constitución Nacional desde 1991, de ahí en adelante existe el reconocimiento a la diversidad sin distingo de género, etnia y color, como a su vez, lo partícipes que deben ser de todos los espacios que brinda el 
Estado. Así mismo, en la Ley 115 de 1994 -Ley General de Educación- se incorporan todas estas figuras inclusivas, que en el espacio escolar, es una forma de ir ejercitando las competencias ciudadanas a los futuros votantes y líderes/lideresas políticos/ cas. De igual manera, en la Ley 823 de 2003, se reconoce que la igualdad de oportunidad es un referente a favor para las mujeres y debe aplicarse desde la primera infancia.

Se concluye que es preponderante que exista el reconocimiento humano, sin diferenciaciones, establecido en Colombia por la Carta Política de 1991, debido a que el consenso constituyente permitió llegar a ese punto, el cual es favorable, para los libres desarrollos de acuerdo a las particularidades personales, lejos de considerar el género, el color y lo étnico, como elemen190 tos marginales, sino más bien, como formas de considerar la valía personal e individual, dentro de lo colectivo y que en conjunto se pueda hacer afirmaciones intrapaís de que todos/as hacen parte de la nación.

Finalmente, lo que arroja la revisión teórica, interpuesta con el análisis del trabajo empírico y documentos legales, confirma, que aún existen limitantes en la participación femenina, tanto de manera externa como interna, que en definitiva hay autodesignación de la mujer ante las heterodesignaciones que históricamente la han separado de espacios públicos; sin embargo, la plataforma institucional potencializa la motivación y activa dentro de ese espacio un resurgir de la mujer contemporánea, en la asunción de su liderazgo, como a su vez el nivel decisorio para continuar el desarrollo de un proyecto de vida, que movilice su saber y pueda desligarla de lo privado, como, de lo reproductivo, establecido como única forma de avanzar en la plenitud femenina. 
En el segundo caso, están inmersos en lo real de la participación y el impacto de las políticas públicas que obstaculizan o facilitan la participación; en ese sentido se concluye en tres puntos: la identificación de políticas públicas en género, la política pública y embarazo adolescente, como también, paridad como integración de géneros. En lo primero, dentro de las abstracciones cognitivas, en cuanto a la identificación de las políticas públicas, que favorecen a la mujer; a través del análisis del canon de los/las directores/as (D), profesores/as $(P)$, personeros estudiantiles (PE) y veedores estudiantiles (VE), existen algunas diferenciaciones entre los/las actores. Primero: los D y $\mathrm{P}$, identifican lo establecido desde la Constitución Nacional y Ley 115, en cuanto a lo determinado para participación general y estudiantil. Segundo: los PE, aunque no las enuncian, determinan que las políticas públicas están a favor de la mujer. Acciones como la prevención de la violencia de género y la igualdad de oportunidades, que corresponde a las Leyes 1257 y 823, delimitadas por el Congreso colombiano, en los años 2008 y 2003, respectivamente; y tercero: los VE, coinciden con los PE, en cuanto al reconocimiento de la importancia que imparten las leyes para la prevención de la violencia de género y la igualdad de oportunidad, como también las diferenciaciones entre lo público y lo privado. A continuación se amplían los conceptos referidos por los/las actores participantes.

En lo segundo, existe conexión entre la política pública que implementa las instituciones públicas de salud y el porcentaje de embarazo adolescente; se ejemplifica en el lugar donde existen mayores embarazos adolescentes, en la IE 21, donde hay baja incidencia de los programas de salud sexual y reproductiva, tanto de parte interna como externa. Siendo este un lugar Rural 
Urbano (RU), se contrapone a las demás IE, del nivel Urbano (U), Rural Rural (RR) y Rural Étnico (RE), donde sí llegan los programas y además tienen estrategias educativas adecuadas para bajar la incidencia de los embarazos adolescentes.

En lo tercero, se deduce que hay un nivel aspiracional de paridad, la cual creen que puede ser benéfica, en torno a la igualdad y los derechos, que según los líderes estudiantiles, tanto PE como VE, creen que puede ser útil. En las IE 2 y 3 coinciden los/ las VE, de la importancia de la paridad en la participación y liderazgo estudiantil, lo cual según los/las VE, facilitaría disminuir la prevalencia de la dominación masculina (VE2). De otro modo, basado en el concepto de derechos, potenciarían la intervención social para buscar alternativas de solución que beneficien 192 a la colectividad (VE3). De esa manera, de parte del consenso de los/las $D$ y $P$, hay compromiso para la implementación de la transversalizacion de la igualdad de género institucional; aunque reconocen que es un proceso gradual, se inicia desde interacciones igualitarias, de parte de ellos/ellas hacia los/las estudiantes.

Finalmente, en el cruce intercultural, en relación a la política pública institucional, se concluye que cognitivamente existe una identificación de las legislaciones que promueven la inclusión de género en lo participativo y en otros ítems determinantes como la violencia de género y la igualdad de oportunidades. Aunque también, básicamente todos/as los actores, se refieren a la Constitución de 1991 y la Ley 115 de 1994 como parte de los procesos de integración ciudadana y educativa de la mujer, lo que deja al descubierto el soporte en los derechos que están definidos en la legislación colombiana para el beneficio de la mujer. Se anota también, que hay un análisis crítico en relación a la 
política pública de salud y los índices de embarazos adolescentes, que a mayor ausencia de programas, es mayor el riesgo de los embarazos adolescentes. Es el caso presentado en la zona $\mathrm{RU}$, donde existe un promedio de siete embarazos adolescentes anualmente; contrapuesto a las zonas $U, R R$ y $R E$, donde hay bajos índices o en el último caso, no ha existido embarazo adolescente durante los últimos tres años. De otro modo, proponen los actores/as del estudio, que el fomento de la paridad entre géneros es fundamental como medio y fin para que las estudiantes específicamente puedan mantener su liderazgo y motivación para participar, lo cual es benéfico, considerando que es necesario que se concienticen tanto hombres como mujeres para el logro de la integración femenina en los espacios políticos y que de lo legal a lo real sea puesto en práctica.

\section{REFERENCIAS BIBLIOGRÁFICAS}

Amorós, C. (1991). Hacia una crítica de la razón patriarcal. Barcelona: Anthropos.

Armentia, P. G. (2007). Un estudio sobre la IV Conferencia mundial de las mujeres. Revista Comunicacion y hombre, (3), 8194.

Barrera, L. (2007). Movimiento feminista en Colombia y su influencia en la salud de las mujeres. Salud, historia y sanidad, (3), 38-49.

Basile, T. (2001). Educación y política. La Universidad Popular de las Madres de Plaza de Mayo: emergencia de nuevas prácticas en cultura y poder. Revista Venezolana de Economía y Ciencias Sociales, 131-150.

Bauman, Z. (2003). Comunidad. En busca de seguridad en un mundo hostil. Madrid: Siglo XXI de España Editores.

Blanchard, L. (2004). La crisis del sujeto desde el feminismo filosófico. Recuperado de: http://sedici.unlp.edu.ar/handle/10915/17528. 17 de febrero de 2017 
CEPAL (1989). Mujer y política: América Latina y el Caribe. Santiago de Chile: Naciones Unidas.

CEPAL (1996). Formación de los recursos humanos femeninos: prioridad del crecimiento y de la equidad. Santiago de Chile: Naciones Unidas.

CEPAL (1998). La educación de las mujeres: de la marginalidad a la educación. Santiago de Chile: Naciones Unidas.

CEPAL (2003). Género, previsión y ciudadanía social en América Latina. Santiago de Chile: Naciones Unidas.

CEPAL (2003). Gobernabilidad democrática y género, una articulación posible. Santiago de Chile: Naciones Unidas.

CEPAL (2010). Agendas legislativas y parlamentarias para el desarrollo de los derechos de las mujeres en América Latina y el Caribe. Santiago de Chile: Naciones Unidas.

CEPAL (2011). Paridad política en América Latina y el Caribe. Percepción y opiniones de los líderes de la región. Santiago de Chile: Naciones Unidas.

CEPAL (2013). Estudio económico de América Latina y el Caribe 2013: tres décadas de crecimiento. Recuperado de http://www. cepal.org/es/publicaciones/1085estudio-economico-de-america-latina-y-el-caribe-2013-tres-decadas-de-crecimiento

Cobo, R. (2006). Interculturalidad, feminismo y educación. Barcelona: Cataratas.

Cobo, R. (2008). Educar en la ciudadanía. Madrid: Cataratas.

Contreras, C. \& Pérez, A. (2011). Participación invisible: niñez y prácticas participativas emergentes. Revista Latinoamericana de Ciencias Sociales, Niñez y Juventud, 2(9), 811-825.

Cornejo, R. (2003). ¿Feminismo posfeminista? Reflexiones culturales a propósito de "Recuerda cuerpo" de Marina Mayoral. Bulletin of spanish studies, $L X X X(5), 598-602$.

Damas de Blanco, (2003). Recuperado de http://www.damasdeblanco.com

De Gouges, O. (1789). Declaración de los derechos de la mujer 
y de la ciudadana. Recuperado de http://clio.rediris.es/n31/ derechosmujer.pdf

De Gouges, O. (1791). Declaración de los derechos de la mujer y de la ciudadana. Recuperado de https://www.marxists.org/ espanol/tematica/mujer/autores/gouges/1791/001.htm

Femenias, M. (2007). El Género del Multiculturalismo. Buenos Aires: Quilmes Editores.

Habermas, J. (1999). La inclusión del otro. Estudios de Teoría política. Buenos Aires: Paidós.

Hierro, G. (1995). Diálogo sobre filosofía y género. México D.F.: Universidad Autónoma de México.

Javaloy, F. (2001). Comportamientos colectivos y movimientos sociales. Madrid: Leavel S.A.

Korenman, J. (2013). Universidad de Maryland, EE.UU. Recuperado de http://userpages.umbc.edu/ korenman/wmst/programs.html\#outside

Kymlicka, W. (1996). Ciudadanía Multicultural. Barcelona: Paidós.

Kymlicka, W. (2010). Ciudadanía Multicultural. Barcelona: Paidós.

Lamus, D. (2009). Movimiento feminista o movimiento de mujeres en Colombia. Medellín: Mujer con voz, la política sí va, pp.120-134.

León, M. (1982). Debate sobre la mujer en América Latina y el Caribe. Bogotá: ACEP.

Luna, L. (1998). Los movimientos de mujeres: feminismo y feminidad en Colombia (1930-1943). España: Universidad de Barcelona.

Luna, L. (1999). La feminidad y el sufragismo colombiano durante el período 1944-1948. Anuario Colombiano de Historia y de Cultura, 26, 194-2012.

Luna, L. (2000). El logro del voto femenino en Colombia: la violencia y el paternalismo populista (1949-1957). Ponencia presentada al XI Congreso Colombiano de Historia. Bogotá 2225 de agosto, 2000. 
Ministerio de Educación (2015). Ley 115 de 1994. Recuperado de http://www.mineducacion.gov.co/1621/article-85906.html Molyneux, M. (2003). Movimiento de las mujeres en América Latina. Estudios teóricos comparados. Madrid: Ediciones Cátedra.

OEA (2010). La participación de los niños y niñas en las Américas. Montevideo: OEA. Recuperado de http://www.iin.oea.org/pdfiin/A-20-anos-de-la-Convencion.pdf

OIT (2004). La mujer y el derecho internacional: conferencias internacionales. Organización, p.46. México: SRE/UNIFEM/ PNUD.

OIT (2014). Recuperado de http://www.ilo.org/public/spanish/

ONU (1992). Conferencia de las Naciones Unidas sobre el medioambiente y desarrollo. Recuperado de http://www. un.org/spanish/esa/sustdev/documents/declaracionrio.htm

ONU (1993). Conferencia Mundial de los derechos humanos. Viena.

ONU (1994). Informe de la Conferencia Internacional sobre la Población y el Desarrollo. El Cairo. New York: Naciones Unidas.

ONU (2002). Objetivos del Desarrollo del Milenio. Recuperado de http://www.un.org/es/millenniumgoals/

ONU (2012). Oficina del Alto comisionado de las Naciones Unidas para los derechos humanos. Recuperado de http://www2. ohchr.org/spanish/law/cedaw.htm

ONU Mujeres (2011). El progreso de las mujeres en el mundo. New York.

ONU Mujeres (2012). Informe anual de la ONU. Recuperado de http://www.unwomen.org/es/digital-library/publications/2013/6/ annual-report-2012-2013

ONU Mujeres (2016). Conferencias de la mujer (1975-1995). Recuperado de http://www.unwomen.org/es/how-we-work/intergovernmental-support/world-conferences-on-women 
Pateman, C. (1998). El contrato sexual. Barcelona: Anthropos.

PNUD (2008). Empoderadas e iguales. New York: Consolidated Graphics.

PNUD (2012). Informe del milenio 2012. New York: ONU.

PREAL (Progreso Educativo en América Latina) (2006). Una revisión a la participación escolar en América Latina. Santiago de Chile: San Marino.

Presidencia de la República (2016). Constitución Política de CoIombia 1991. Recuperado de http://wsp.presidencia.gov.co/ Normativa/Documents/Constitucion-Politica-Colombia.pdf

Presidencia de la República (2016). Leyes colombianas. Recuperado julio 29 2016: http://es.presidencia.gov.co/normativa/ leyes (2016, 29 de julio).

Sánchez, C. (2005). Los gobiernos escolares y estudiantes en Honduras. Estudio de su organización y funcionamiento en municipios de cinco departamentos. Tegucigalpa: UNICEF.

Taller feminista (2013). Recuperado de http://tallerfeminista.files. wordpress.com/2009/05/introduccion-a-la-segunda-jornada. pdf

Taylor, C. (1993). El multiculturalismo y política del reconocimiento. México: Fondo de Cultura Económica.

UNESCO (2000). Adopción de marco de acción Dakar. Recuperado de: http://unesdoc.unesco.org/images/0012/001211/121147s.pdf

UNESCO (2000). Educación para todos en Jomtien. Recuperado de http://www.unesco.org/new/es/our-priorities/education-for-all/

UNESCO (2014). Informe Unesco 2014 sobre la igualdad de género y la cultura. Recuperado de http://www.unesco.org/new/ es/culture/gender-and-culture/gender-equality-and-culture/ the-report/

UNICEF (1998). La participación de niños y adolescentes en el contexto de la convención sobre los derechos del niño: visio- 
nes y perpectivas. Bogotá.

UNICEF (2006). Hacia una escuela de calidad amiga de las niñas y niños. Ideas para la acción. Bogotá: Fondo de Naciones Unidas para la Infancia.

Velázquez, M. (1995). Las mujeres en la historia de Colombia. Bogotá: Grupo Editorial Norma.

Viezzer, M. (1968). Si me permiten hablar... Testimonio de Domitila, una mujer de las minas de Bolivia. México: Siglo XXI Editores S. A.

Wollstonecraft, M. (2005). Vindicación de los derechos de la Mujer. Madrid: Fernández Editores. 